\title{
Interspecific Variation in Seasonal Migration and Brumation Behavior in Two Closely Related Species of Treefrogs
}

\section{OPEN ACCESS}

Edited by:

Brett K. Sandercock,

Norwegian Institute for Nature

Research (NINA), Norway

Reviewed by:

Kristine Elizabeth Hoffmann,

St. Lawrence University, United States

Ivan Gomez-Mestre,

Estación Biológica de Doñana (EBD),

Spain

*Correspondence: Amaël Borzée

amaelborzee@gmail.com

Piotr G. Jablonski

piotrjab@behecolpiotrsangim.org

Yikweon Jang

jangy@ewha.ac.kr

Specialty section:

This article was submitted to Behavioral and Evolutionary Ecology,

a section of the journal

Frontiers in Ecology and Evolution

Received: 13 May 2018 Accepted: 15 February 2019 Published: 11 March 2019

Citation:

Borzée A, Choi Y, Kim YE Jablonski $P G$ and Jang Y (2019) Interspecific Variation in Seasonal Migration and Brumation Behavior in Two Closely Related Species of Treefrogs. Front. Ecol. Evol. 7:55. doi: 10.3389/fevo.2019.00055

\begin{abstract}
Amaël Borzée ${ }^{1,2 *}$, Yoojin Choi $^{2}$, Ye Eun Kim ${ }^{2}$, Piotr G. Jablonski ${ }^{1,3 *}$ and Yikweon Jang ${ }^{2 *}$
${ }^{1}$ Laboratory of Behavioral Ecology and Evolution, School of Biological Sciences, Seoul National University, Seoul, South Korea, ${ }^{2}$ Division of EcoScience, Department of Life Sciences, Ewha Womans University, Seoul, South Korea, ${ }^{3}$ Museum and Institute of Zoology, Polish Academy of Sciences, Warsaw, Poland
\end{abstract}

Most amphibians migrate between flooded habitats for breeding and dry habitats for non-breeding activities, however, differences in closely related species may highlight divergent evolutionary histories. Through field surveys, Harmonic Direction Finder tracking and laboratory behavioral experiments during the wintering season, we demonstrated differences in seasonal migration and hibernation habitats between Dryophytes suweonensis and $D$. japonicus. We found that $D$. japonicus migrated toward forests for overwintering and then back to rice paddies for breeding in spring. By contrast, D. suweonensis was found to hibernate buried in the vicinity of rice paddies, its breeding habitat. We also found that the difference in migrating behavior matched with variation in microhabitat use during brumation and hibernation between the two species. Our findings highlight different ecological requirements between the two species, which may result from their segregated evolutionary histories, with speciation potentially linked to species use of a new breeding habitat. Additionally, the use of rice paddies for both breeding and hibernation may contribute to the endangered status of $D$. suweonensis because of the degradation of hibernation sites in winter.

Keywords: brumation, Dryophytes japonicus, Dryophytes suweonensis, hibernation, hylids, migration

\section{INTRODUCTION}

Most amphibians migrate between flooded habitats for breeding and dry habitats for non-breeding activities. Differences among species in the details of these seasonal variations may highlight divergent evolutionary histories (Wake, 1982), although intraspecific variations in life-history strategies are widespread (Collins, 1981; Miaud et al., 1999), and traits covary with environmental gradients such as elevation and latitude (Morrison and Hero, 2003). In amphibians, aquatic breeding is the shared ancestral character for all species (Wake, 1982; Reiss, 2002; Schoch, 2009). Thus, migration between breeding and overwintering habitats is an evolutionary requirement tied to the biphasic life cycle of a large number of amphibians (Duellman and Trueb, 1986). The medium used for breeding typically reflects the ancestral character (Duellman, 1989), whereas migration toward different environments is a more recent evolutionary trait (Semlitsch, 2008). Exceptions do exist, however, such as for plethodontid salamanders, which retain the larval stage (Chippindale et al., 2004), and for one of the focal hylid species of this study for yet unknown reasons.

Differences in life cycles are one of the indicators of divergence in evolutionary origin between related species (West-Eberhard, 2003, 2005). Novel phenotypes stem from the reorganization of 
ancestral phenotypes, followed by the genetic accommodation of changes (Mayr, 1963; West-Eberhard, 2005). Selection acts on phenotypes (Mayr, 1963), and thus populations subjected to differential environmental pressure may see the apparition of specific phenotypes that are subsequently integrated into genotypes (West-Eberhard, 2005). This includes for instance the tropical vine Monstera sp., which displays varying leaf forms, resulting in species-specific ontogenies (Madison, 1977). It is also the case with role-reversed sandpipers species where males incubating eggs show the same increase in prolactin as incubating females (Beach, 1961; Oring et al., 1986). Another example is the interspecific variation in parental care due to ecological requirements in Microtus spp. (West-Eberhard, 2003). However, selected phenotypes may arise from the pressure exerted by environmental drivers. For instance, fisheries result in the selection of individuals through both direct and indirect pressures (Heino and Godø, 2002). Direct selection pressure includes elevated mortality of target species, while indirect selection is exemplified by ecosystem-level impacts as intakes result in depleted resources (Kaiser and De Groot, 2000). Similarly, phenotypic plasticity is one of the reasons for the expression of different phenotypes between populations. For instance, local adaptation to climate can result in different range dynamics (Atkins and Travis, 2010).

Seasonal migration is only one type of population displacement (Semlitsch, 2008; Cayuela et al., 2018), but it is the most common non-circadian migration, observed from whales (Kenney et al., 2001) to butterflies (Brower, 1995). Seasonal migration is also common in amphibians (Sinsch, 1990; Ryan and Semlitsch, 1998); for instance, Bufo bufo hibernates in terrestrial hibernacula (Van Gelder et al., 1986; Denton and Beebee, 1993) and migrates to water bodies to breed in spring (Gittins, 1983). Some amphibian species will migrate considerable distances from their breeding site to find shelter against climatic variation (Griffiths, 1984), although $15 \mathrm{~km}$ is considered the limit for direct migration and dispersion due to physiological requirements (Sinsch, 1990; Cayuela et al., 2018). A representative assessment of eight Central European amphibian species demonstrated migration distances between roughly 100 and 2,200 $\mathrm{m}$ from the breeding site (Kovar et al., 2009). Other species, such as Lithobates catesbeianus, hibernate in the vicinity of their breeding sites and thus do not require migration (Stinner et al., 1994). Migration is generally observed between breeding and over-wintering sites, where species will shelter from inclement condition through torpor. While over-wintering strategies are diverse (Storey and Storey, 2017), and include under-water (Penney, 1987) and below-ground sheltering (Borzée et al., 2018c), information about brumation or hibernation for a large number of species is still missing. Here, brumation refers to the pre-hibernation period, and although yet poorly described in metabolic terms in amphibians (Feder and Burggren, 1992; Balogová et al., 2017; Wilkinson et al., 2017; Kundey et al., 2018) with the exception of Salamandra salamandra (Catenazzi, 2016), it refers to the pre-winter reduced activity and reduced metabolic rates of poikilotherms (Hutchinson, 1979; Pratihar and Kundu, 2011; McEachern et al., 2015). When focusing on over-wintering in treefrogs, field observations provide the most reliable data for European species (reviewed by Stumpel, 1990), complemented by behavioral ecology studies on North American species (Mahan and Johnson, 2007; Johnson et al., 2008). In addition, some Indian species are known to shelter from the cold in banana stems (Iangrai, 2011). Dryophytes japonicus in North East Asia is comparatively well studied and known to start hibernating because of the rise of cirp RNA due to cold and photoperiod (Sugimoto and Jiang, 2008). In addition, the species is able to withstand massive temperature drops, down to $-53^{\circ} \mathrm{C}$ in laboratory settings (Berman et al., 2016), and to principally use forested hills for hibernation (Borzée et al., 2018c).

In amphibian species in the Republic of Korea, both aquatic and dry types of non-freeze-resistant hibernation types are known. For instance, Rana spp. can hibernate under water (Lee and Moon, 2011; Macias et al., 2018) and are the first species present at the breeding sites after ice thaw (Yoo and Jang, 2012; Macias et al., 2018). In contrast, Dryophytes japonicus hibernates under decaying vegetation on hills principally forested by oak trees (Borzée et al., 2018c). It is unclear if the other treefrog species from the peninsula, the endangered $D$. suweonensis, can follow the same pattern. Unlike D. japonicus, the species is not found in forests during the non-breeding season. Furthermore, there are anecdotal observations of $D$. suweonensis hibernating in the banks of rice paddies (Pers. Comm. Kim Hyun-Tae). Dryophytes suweonensis is known to have originally bred in low-altitude alluvial wetlands, but it is now restricted to rice paddies (Borzée and Jang, 2015), whereas D. japonicus breeds in a much wider range of environments as long as solid substrate is available for call production (Borzée et al., 2016b). In addition, the two species display microhabitat segregation during the production of advertisement calls, likely due to competition (Borzée et al., 2016b). Given the long list of traits linked to the species' breeding behavior (Roh et al., 2014; Borzée and Jang, 2015; Borzée et al., 2015a, 2016a, 2017a; Kim, 2015b, 2016), we hypothesize that $D$. suweonensis hibernates in rice paddies, where it also breeds, whereas D. japonicus is expected to migrate seasonally between breeding sites and the forests hills where it hibernates. Here, we tested the hypothesis through winter field surveys of the two Dryophytes species. Interestingly, the pattern hypothesized is known to be similar to the one displayed in other amphibians where one of the two closely related species is restricted to rice paddies (Pelophylax nigromaculatus and $P$. porosus brevipodus in Japan Maeda and Matsui, 1993). The absence of seasonal migration may indicate that the two species share the same breeding and overwintering habitats, and thus exploit the same environment, whereas differences in seasonal migration would suggest a different evolutionary history and the use of different environments.

\section{MATERIALS AND METHODS}

This project is composed of 5 distinct sections consisting of experiments, field tracking and observations for both Dryophytes suweonensis and D. japonicus: (1) field observations for brumation, (2) field orientation tracking for brumation, (3) 
laboratory brumation and hibernation observations, (4) winter field observations and finally, (5) spring orientation tracking. Here, we define brumation as the pre-hibernation period during which amphibians are partially active (Mayhew, 1968; Pratihar and Kundu, 2011; McEachern et al., 2015), and such as defined for one of the two focal species, D. japonicus, by Borzée et al. (2018c). The five sections used to distinguish between experiments are based on the seasonal succession of activities, from prehibernation to emergence from hibernation. We conducted all experiments with the agreement of the Ministry of Environment from the Republic of Korea under permit numbers 2013-16, 2014-04, 2014-08, 2014-20, 2015-3, 2015-4, 2015-6, 2015-28, and 2016-5.

Dryophytes suweonensis is slender and smaller than D. japonicus (Borzée et al., 2013), and the earlier species is active earlier in the afternoon than the latter, although both species are principally active at night (Borzée et al., 2016b). Dryophytes japonicus is widespread on the Asian mainland until central Mongolia and the Baikal lake region in Russia (Dufresnes et al., 2016; Kuzmin et al., 2017) but the two species only co-occur on the western lowlands of the Korean Peninsula, where the distribution of $\mathrm{D}$. suweonensis is restricted to agricultural wetlands due to widespread habitat modification (Roh et al., 2014; Borzée and Jang, 2015; Borzée et al., 2015a, 2018a; Borzée and Seliger, 2018). The use of rice paddies impacts the breeding behavior of both species (Borzée et al., 2018b; Groffen et al., 2018), which display both temporal and spatial segregation during the breeding season (Borzée et al., 2016a,b). The population decline of $D$. suweonensis is principally linked to habitat loss (Borzée, 2018; Borzée et al., 2018a), but other factors such as hybridization (Borzée and Jang, 2018), sensitivity to water quality (Borzée et al., 2018f), behavior (Borzée et al., 2018g), and invasive species and pathogens (Borzée et al., 2017b) are involved (Borzée et al., 2017a; Borzée, 2018).

\section{Field Observations for Brumation}

We collected field observations on the brumation ecology of the two species at two localities in $2014(n=29)$ and four in 2015 ( $n=32$; Figure 1). The two localities from 2014 (\#1 and $\# 2$; Figure 1) are included within the four localities from 2015 (together with remaining sites \#3 and \#4; Figure 1). Locality 1 is composed of one paddy site and two forested sites, and localities 2,3 , and 4 are each composed of one paddy site and a single forested site. We selected the localities following observations of calling males of both Dryophytes species during the breeding season (see Borzée and Jang, 2015).

We initiated the surveys in September of both years and continued until the first freeze. In 2014, we surveyed the sites in the first and third weeks of September, every week in October and the first week of November. In 2015, we surveyed all sites in the third week of September, the first and third weeks of October and the first week in November. We conducted the surveys through spotlight line transects (Smith and Nydegger, 1985), by which the researcher followed a predetermined transect and visually inspected the vegetation for individuals. The transects at the rice paddy sites were conducted for varying distances along the straight cement road at the center of rice-paddy complexes

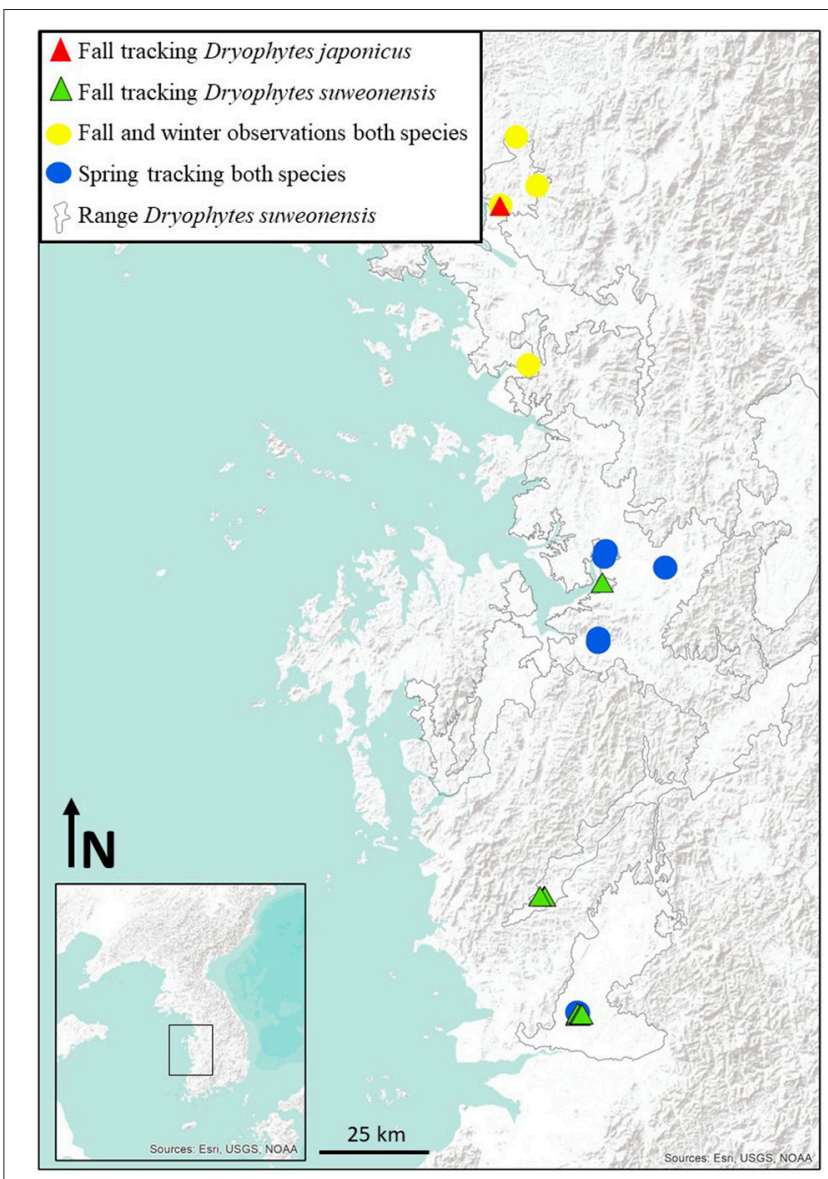

FIGURE 1 | Spatial location of the sites surveyed in this study. The map was generated with ArcMap 9.3 (Environmental Systems Resource Institute, Redlands, California, USA; http://www.esri.com/) and the range of the species is extracted from Borzée et al. (2017a).

(Figure 2; Borzée and Jang, 2017). We conducted the transects at the forest sites along a 250 -m approximately straight line due to the topology of the field. Each hylid frog found was hand caught, and the species identified based on morphology (Borzée et al., 2013) when calls were not available (Park et al., 2013). We detected D. suweonensis during 20 surveys, and D. japonicus during 29 surveys.

\section{Field Orientation Tracking for Brumation}

For all microhabitat use and directionality experiments in this study, we used a Harmonic Direction Finder (HDF; R2 RECCO $\mathrm{AB}$; Lidingö, Sweden), relying on a passive dipole attached to the individual to be tracked with a gauze waist band. The HDF emits microwaves toward the dipole, which bounces them back through an antenna tailored for each individual and encodes for directionality and distance (Pellet et al., 2006; Pašukonis et al., 2014; Borzée et al., 2016b). We soldered a Schottky diode (model R2 RECCO AB; Lidingö, Sweden) on a tin-plated copper wire folded on itself at $180^{\circ}$ in a fashion that created a loop $1 \mathrm{~cm}$ away from the bent, prolonged by two isolated segments 


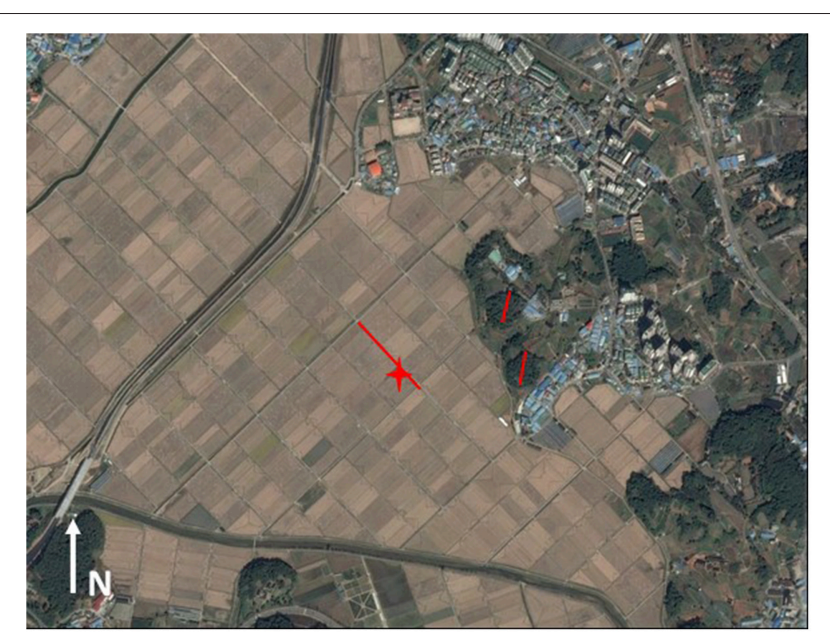

FIGURE 2 | Example of the brumation and winter field observations at site \#1, Sihung, located $37.406^{\circ} \mathrm{N}$ and $126.805^{\circ} \mathrm{E}$. The red lines represent the transects, in the rice paddies in the west and in the forests in the east. The red star indicates the site where the hibernating female was found during the winter field observations. This map was generated with Google Earth Pro (v7.1.2.2041, 2013) on maps from 2016 SKEnergy, Image Landsat Copernicus

of the wire, resulting in an antenna. This design maintains the electric properties of the diode and provides mechanical elasticity in the antenna. The Schottky diode reflects the wave received at twice its frequency (see de Moura Presa et al., 2005; and Borzée et al., 2016b for details), which the HDF then translates into an acoustic signal of varying intensity in function of the direction and distance to the dipole, thus allowing for locating the organism that is wearing the antenna. To isolate the electrical dipole, we uniformly insulated each antenna with a silicone spray (NABAKEM, S-830 UL94 V-0, Seoul, Korea).

We selected the initial antennae with two 8-cm legs, resulting in an approximately $25-\mathrm{m}$ effective range. We prepared the waistbands to which the antennae were attached with different lengths for each individual to ensure that each antenna weight was below the recommended 5\% of each individual's body mass.

The protocols used here to investigate migration patterns (i.e., directionality) are following standard procedures, similar to those used to determine bird and insect directionality during migration. The protocols for birds are described in Emlen and Emlen (1966), Emlen and Emlen (1966) and have been widely used in birds and insects (Wiltschko et al., 1993, 2008; Able and Able, 1995; Benvenuti et al., 1996; Eng et al., 2017). Studies on amphibian migrations and orientation usually rely on setting such as drift-fence and pit-fall traps (Johnson, 2003; Todd et al., 2009; Santos et al., 2010; Lenhardt et al., 2015), emigration pattern field-data collection (Lenhardt et al., 2013), or indirectly through road-kills (Elzanowski et al., 2009). In addition, amphibian movements can also be studied through telemetry (Baldwin et al., 2006; Pellet et al., 2006; Borzée et al., 2018d) and orientation has also been studied through HDF tracking (Pašukonis et al., 2013; Pašukonis et al., 2014).
Tracking during brumation was conducted separately for the two treefrog species. HDF tracking was conducted in 2013 for $D$. japonicus because the species was already known to be hibernating on forested hills (Sugimoto and Jiang, 2008; Borzée et al., 2018c). However, we collected the first anecdotal observation on the overwintering of D. suweonensis in 2015, following which we conducted brumation tracking.

We released and tracked each frog for $24 \mathrm{~h}$, thus including both diurnal and nocturnal activities. Releases were conducted after sunset, at least $15 \mathrm{~m}$ from each other to prevent detection overlap. For each tracking point, we placed a colored flag approximately $10 \mathrm{~cm}$ from the frog to measure the displacement and directionality of the movement between successive points. Every hour, we recorded temperature $\left({ }^{\circ} \mathrm{C}\right)$, luminosity (lux), relative humidity $(\%)$, height from the ground $(\mathrm{cm})$, distance moved from the previous point $(\mathrm{cm})$ and type of microhabitat. The five types of microhabitats were "grass," "rice," "buried," "ground," and "bush." We also noted the directionality of the movement, toward either the center of the forest or the center of the adjacent rice paddies. The movement was decomposed in the form of a vector, for instance, $50 \mathrm{~cm}$ toward the forest and $20 \mathrm{~cm}$ toward the rice paddies. We took all measurements at $5-\mathrm{cm}$ resolution to avoid overly disturbing the frogs.

\section{Dryophytes japonicus}

For this experiment, the waistband to attach the antenna to the frogs was made of gauze sewed onto itself ventrally and it was thus adjusted for the size of each individual. We tracked nine males and one female D. japonicus in the city of Paju (red marker; Figure 1), on September 27 to 30, 2013. As it is difficult to catch adults once they have reached their hibernation habitat, individuals had been previously caught in the forest adjacent to the rice paddy complex (see Borzée et al., 2018c) and raised for 1 month under controlled conditions in the lab. We released each individual at the edge of a rice paddy between 174 and $209 \mathrm{~m}$ away from the edge of the forest where it had been caught. We tracked individuals for $2328.33 \pm 719.63 \mathrm{~min}$ on average (ca. $39 \mathrm{~h}$ ), resulting in an average of $125.98 \pm 17.70 \mathrm{~min}$ (mean \pm S. D.; ca. $2 \mathrm{~h}$ ) between tracking points, for a total of 172 observations.

\section{Dryophytes suweonensis}

For this experiment, each waistband was made of silicone tubing (diameter $=1.8 \mathrm{~mm}$ ) within which we inserted the loop of the antenna. The loop was connected ventrally with electrical paint (BareConductive $10 \mathrm{ML}$, Bare Conductive Ltd; London, UK) and thus worked as an electric dipole that was tailored for the size of each individual. We tracked four individuals of each sex at four independent sites over a 110-km range (green markers, Figure 1) between October 8 and 16, 2015. Individuals had been caught $\sim 1$ month earlier at the same site (Kim, 2016; Borzée et al., 2018e) and had been raised in controlled laboratory conditions before their release. We released each individual at the edge of a rice paddy between 139 and 1,018 $\mathrm{m}$ away from the edge of the closest forest, and we tracked individuals for $1,332 \pm 120 \mathrm{~min}$ on average (ca. $20 \mathrm{~h}$ ), for a total of 305 observations. 


\section{Laboratory Brumation and Hibernation Observations}

We conducted two experiments under laboratory conditions for both species, the first one on microhabitat selection during brumation, referred to as "lab brumation," and the second one on microhabitat selection during hibernation, referred to as "lab hibernation." For both species, the individuals originated from egg masses that we collected from the wild (Kim, 2016; Borzée et al., 2018e) and were kept in the lab from hatching to release (permit 2015-4 issued by the Ministry of Environment of the Republic of Korea). For this experiment, we collected five individuals from five egg masses at five different locations (blue markers, Figure 1; $n=25$ for each species) and raised the tadpoles in independent PVC aquariums $(20 \mathrm{~cm} \mathrm{~W} \times 30 \mathrm{~cm}$ $\mathrm{L} \times 20 \mathrm{~cm} \mathrm{H}$ ). After metamorphosis, individuals were isolated, providing a sample size of five individuals raised independently for each of the five families for each species. Each metamorph was raised in a glass terrarium $45 \times 45 \times 45 \mathrm{~cm}$ with a lateral opening, transparent sides, and a screen top (PT2605, Exo-terra, Hagen, Montreal, Canada).

We set all terraria with wet towels at the bottom that were changed weekly or more often if needed. We also set a conic non-glazed terra cotta pot $(25 \mathrm{~cm}$ height $\times 16 \mathrm{~cm}$ diameter $)$ horizontally at the back left of each terrarium and set a glazed water-dish $(3 \mathrm{~cm}$ deep, $12 \mathrm{~cm}$ diameter $)$ at the front right, with a $5 \times 3 \mathrm{~cm}$ non-glazed terra-cotta cylinder pot set upside down within the water dish. The arrangement allowed for the terra cotta pots to absorb water and release it through evaporation within the terrarium to keep the humidity relatively constant $(48.48 \pm 11.18 \% \mathrm{rH})$. Finally, we set a wooden cylinder $(2.5 \mathrm{~cm}$ diameter) from the bottom front left corner to the top back right corner. We used oak cylinders on $D$. japonicus known preferences (Borzée et al., 2018c). We set the terraria onto two four-layered shelves, with their position randomized every second week. Each terrarium was illuminated by its own lighting (UV-B bulbs), and we estimated that the positions of the terraria did not result in any bias in the experiments.

Each of the 50 terraria was sprayed daily and the water dish refilled ad libitum with carbon filtered and 72 -h evaporated water. The frogs were set on a circadian cycle that matched the natural one, readjusted weekly, under natural spectrum illumination. Crickets were the main diet items used to feed the frogs, but fruit flies and maggot supplements were also given when available. All prey items were powdered with calcium and multivitamins prior to use.

For both brumation and hibernation experiments, we recorded the position of the individual, i.e., substrate use, and its height from the bottom of the terrarium three times a day (variable: "time period"). We also collected date, time, temperature $\left({ }^{\circ} \mathrm{C}\right)$ and relative humidity (\%) for each survey point. We noted temperature and humidity readings once for all 50 terrarium replicates because they were set in a common rearing room that was exposed to controlled climatic variations that followed natural variations (see Borzée et al., 2018e for details). There were five categories of microhabitat in each aquarium: big pot (on or within the large terra cotta pot, representative of sheltering behavior), ground (anywhere on the paper towel, representative of ground microhabitats), wood (sitting on the wood cylinder, representative of perching behavior on wooden microhabitats, as known to be important for D. japonicus brumation; Borzée et al., 2018c), pot in water (representative of flooded or damp habitat, as known to be important for D. suweonensis brumation, earlier in this study), and glass (when an individual was resting on a glass panel, not representative of any wild habitat but included to prevent any bias in further analysis). Whenever we made an observation, we noted the microhabitat the individual used.

We conducted the brumation experiment between September 23 and October 16, 2015, leading to a total of 1,906 observations, and we conducted the hibernation experiment between December 1 and 23, 2015, for a total of 1,612 observations.

\section{Winter Field Observations}

The purpose of this set of observations was to observe frogs of both species hibernating in their natural environments. We revisited the four sites where we had conducted brumation observations in the third week of January 2015 to look for buried individuals. We spent a total of $4 \mathrm{~h}$ at each of the four sites digging the soil down to $50 \mathrm{~cm}$ in the areas where the frogs of the two species had last been seen. The areas searched were about $2 \mathrm{~m}^{2}$ for each observation, and matched with the areas where the frogs were last seen (Borzée and Jang, 2017), based on the assumption that home range and breeding ranges may be similar (Kim et al., in press).

\section{Spring Orientation Tracking}

For this section, the tracking methodology was the same as used for orientation experiments (Section Field Orientation Tracking for Brumation). The frogs used for this experiment were animals we had raised from hatching and had used for the two lab experiments. We had maintained them in the setting described above until the beginning of tracking experiments, and we released them after finishing the spring orientation tracking experiments. The sites for the experiment, which aimed at determining the post-hibernation behavior of the two treefrog species, were distributed along the whole range of $D$. suweonensis (blue markers, Figure 1). The sites were the same as the sites where we had collected the egg masses. The tracking procedure in the spring tracking experiment was the same as that of the fall tracking for D. suweonensis.

We conducted the fieldwork between May 25 and June 17, 2016 , for a total of 20 individuals from each species. We released ten individuals of each species in rice paddies and the remaining ten in forested areas at the edge of rice paddies. The forest was composed of Chinese chestnuts (Castanea spp.) and pine trees (Pinus spp.) where D. japonicus is typically found during the nonbreeding season (Borzée et al., 2018c). We checked the position of each individual every hour and we took note of date, time of day, GPS coordinates, vegetation type, temperature, humidity, height, total movement and movement toward rice paddies and forest. We assessed the directionality based on movements toward the selected landscape features. We spent an average of $22.07 \pm 2.32 \mathrm{~h}$ ( $n=25$ for each species) tracking per individual (duration \pm SD). As all individuals were tracked for over $16 \mathrm{~h}$, all were included in 
the subsequent analyses. The microhabitats recorded were grass, rice, buried, ground, and bush. We tracked a maximum of 5 individuals at the same time, and avoided tracking individuals within $50 \mathrm{~m}$ of each other to prevent overlap in HDF detection signal. We released each individual between 20:00 and 00:00 to minimize possible predation due to the tracking apparatus.

\section{Data Analysis}

After the tracking experiments, we mapped the GPS coordinates for all tracked points for each individual on Google Earth (Google, Mountain View, USA). For each data point, we then measured the directionality of the movement, such as the angle between the forest, the tracking position of the individual and its subsequent tracking position. Here, the forest was defined as a point situated at the center of gravity of 10 points randomly chosen on the edge of the forest. Because we had released all individuals at different points and their orientation toward landscape elements was our prime focus, and not directionality toward cardinal points, we defined 0 degrees as toward the forest. We set this point arbitrarily for ease of graphical interpretation and because individuals rarely expressed a total change (i.e., 180 degrees) in directionality. Thus, an angle of orientation between 270 and 90 degrees represented a displacement that factored positively toward the forest, an angle of 0 degrees was a straight line toward the forest and an angle of 180 degrees was a straight line away from the forest. We measured all angles on screen with the software imageJ (National Institutes of Health, Bethesda, USA). For ease of analysis for models assessing directionality of migration patterns but not involving interspecies comparisons, the directionality was binary encoded as toward or away from the forest. For other analyses where a binary encoding would not be adequate to describe the behavior of the species, variation in the angle of directionality was analyzed separately with circular statistics.

(1) To assess seasonal variations in occurrence for both species, and compare the occurrence patterns between the two species, we first analyzed the dataset through a repeated-measure ANOVA. To do so, the repeated surveys, continuous variable hereafter defined as "season," were set as the dependent variable with seven levels, corresponding to the seven surveys replicates, while occurrence for $D$. suweonensis and D. japonicus were set as factors. To run this analysis, we tested for homogeneity of variance with Levene's test, and because the error variance was not equal across groups for the sixth replicate only, we ignored the partial violation of assumption for the statistical analysis. We also tested the sphericity assumption with Mauchy's test, and ran the repeated-measures ANOVA with the Greenhouse-Geisser correction (Scheiner and Gurevitch, 2001) because the sphericity assumption was violated. Furthermore, we assumed compound symmetry (homogeneity of the variance-covariance matrix) for this analysis. We then graphically matched the variation in occurrence over weeks for the two species and the type of site with the results of the statistical analysis.

(2) Because there was no correspondence between the data for $D$. japonicus and D. suweonensis, the data for each species was first analyzed in relation with directionality to the forest (details below), and then compared. The fall tracking data for D. japonicus was first tested for the significance of directionality toward forests for individuals. Because data were either temporally or spatially independent, the directionality variable was set as dependent variable in a binary logistic regression. The last assumption was also met in that the individual variable, set as the independent variables, was on a nominal scale.

Once directionality was established, we analyzed the dataset using a univariate General Linear Model (GLM) to find the factors that were important for directionality. Thus, we set directionality as a dependent variable, encoded as toward paddies, toward forests, or no movement; distance traveled as a fixed factor; frog ID, day, time of day and microhabitat as random factors and temperature and luminosity as covariates under a main effect model. After visually testing for the absence of outliers by analyzing box-plots, we determined the normal distribution of the data with the Kolmogorov-Smirnov test for normality with the Lilliefors significance correction $\left(0.14 \leq D_{(151)} \leq\right.$ $0.51, p<0.001)$, and determined the homogeneity of variance with Levene's test for homogeneity of variances $\left[F_{(134,116)}=\right.$ $2.19, p=0.001]$. We did not include relative humidity in the analysis because it was correlated with temperature (Pearson's Correlation, $R=-0.16, p=0.044)$. We subsequently explained all significant variables through descriptive statistics.

We analyzed the fall tracking for D. suweonensis in a similar way as that for $D$. japonicus, first testing for the significance of directionality toward forests for individuals. Because the data were either temporally or spatially independent, we set directionality as the dependent variable in a binary logistic regression. The last assumption was also met in that "individual," set as the independent variable, was on a nominal scale.

We then analyzed our dataset with a GLM to find the factors that were important for directionality. For this model, we set directionality as the dependent variable; distance traveled as a fixed factor; site, sex, and vegetation as random factors and date, time of day, temperature, height, luminosity, and frog ID as covariates, under a main factor effect model. After visually testing for the absence of outliers by analyzing boxplots, we determined the normal distribution of the data with the Kolmogorov-Smirnov test for normality with the Lilliefors significance correction $\left(0.07 \leq D_{(301)} \leq 0.47, p \leq 0.001\right)$, and determined the homogeneity of variance with Levene's test for homogeneity of variances $\left[F_{(136,164)}=4.28, p<0.001\right]$. In this analysis as well, we did not include relative humidity because it was correlated with temperature (Pearson's Correlation; $R=$ $-0.81, n=304, p<0.001)$. The significant variations were then explained through descriptive genetics.

Last, to understand the differences in movement patterns between the two species, we also analyzed the angles described by the movements in relation to forests using circular two-sample geometrical directional analysis. The data were temporally and spatially independent but did not meet the prerequisite assumption of the von Mises distribution (Watson's U2 test; $U 2$ $=1.72, p<0.005$; Lockhart and Stephens, 1985), and we used the non-parametric Mardia-Watson-Wheeler (Mardia, 1972) test with angle as the dependent variable and species as independent 
variables. We ran the analysis under an axial (orientation) model. We conducted this additional test despite the experiments being conducted at different years and at different sites for the two species. We used the results to link the two analyses and highlight the differences between the two species.

(3) We first analyzed the lab brumation experiment dataset using a multinomial logistic regression to detect variation in microhabitat use between the two species. Thus, we set microhabitat as the dependent variable, and the independent variables were species, family, and individual ID nested within family as factors, and temperature, height, time and date as covariates. We did not use humidity in the model because it was correlated with temperature (Pearson's Correlation; $r$ $=0.40, p<0.001)$ and date $(r=0.11, p=0.001)$. We ran the regression under a main-effects model and selected a multinomial logistic regression because assumptions were fulfilled: we did not detect outliers in our analyses of the box-plots. There was a linear relationship between the continuous independent variables and the logit transformation of the dependent variable, tested through the Box-Tidwell (Box and Tidwell, 1962) procedure with Bonferroni corrections (Tabachnick and Fidell, 2014), with $p>0.379$ for all variables, which thus rejected the null-hypothesis. We then described the variation between the different microhabitat and other significant results.

We then analyzed the lab hibernation experiment dataset for microhabitat use in the same way as for the brumation period, because we conducted this experiment in the same setting and collected the type same data. We also ran the multinomial logistic regression in agreement with assumptions: we observed no outliers through the analysis of box-plots, and we did not use humidity in the model because it was correlated with temperature (Pearson's Correlation; $r=0.09, p<0.001)$ and date $(r=$ $0.08, p=0.001$ ). There was a linear relationship between the continuous independent variables and the logit transformation of the dependent variable with $p>0.116$ for all variables.

As the same variables were significantly different for the two species for both phases of the experiment, as tested above, we proceeded to run an additional multinomial logistic regression to assess whether the two species differed in microhabitat use between the two phases of the experiment (i.e., brumation and hibernation). To do this, we set microhabitat as the dependent variable, and for the independent variables, we set phase and species as factors and height as a covariate. The model assumptions were met, we did not detect any outlier, no variables were significantly correlated and there was a linear relationship between the continuous independent variables and the logit transformation of the dependent variable with $p>0.358$ for all variables.

(4) Due to the low number of hibernating individuals found during the field observations, we could not conduct any statistical analysis and the results are descriptive only.

(5) To determine microhabitat preferences and directionality post-hibernation for the two species, we first assessed the correlations between variables to avoid collinearity in subsequent analysis. We detected significant correlations between total displacement and displacement toward paddies (Pearson's correlation; $r=0.20, n=873, p<0.001)$ and between total displacement and displacement toward forest (Pearson's Correlation; $r=-0.26, n=873, p<0.001$ ). The variables ID, date (Pearson's Correlation; $r=0.95, n=873, p<0.001$ ) and sites (Pearson's Correlation; $r=0.96, n=873, p<0.001$ ) were also correlated. Finally, temperature and humidity followed the same trend (Pearson's Correlation; $r=-0.79, n=873, p<$ $0.001)$. Among the correlated variables, we included only one from each group in the subsequent analyses.

We then ran a GLM to determine the differences in directionality between the two species post-hibernation. Thus, the binary encoded directionality was set as the dependent variable, species and ID as fixed factors, habitat as a random factor, and date, time, temperature and height as covariates, under a main-effects model. A few more variables were not included in the model because of collinearity: humidity was correlated with temperature (Pearson's Correlation; $r=-0.78$; $n=873 ; p<0.001)$, total displacement was correlated with directionality (Pearson's Correlation; $r=0.33 ; n=873$; $p<$ 0.001 ), and site type with microhabitat (Pearson's Correlation; $r$ $=-0.41 ; n=873 ; p<0.001)$. We chose a GLM after visually testing for the absence of outliers through the analysis of the box plots, and we determined the normal distribution of the data with the Kolmogorov-Smirnov test for normality with the Lilliefors significance correction $\left(0.14 \leq D_{(151)} \leq 0.51, p<\right.$ $0.001)$. Finally, we determined the homogeneity of variance with Levene's test for homogeneity of variances $\left[F_{(68,804)}=6.03, p=\right.$ 0.001]. The significant differences were highlighted by descriptive statistics, and in addition $T$-tests, circular statistic tests and ad hoc analyses were conducted if required. Due to significant differences in directionality between the two species, we analyzed the differences in displacement angles through a suite of circular two-sample geometrical directional analyses, two-by-two for the variables: species, release habitat and angles. Because the data were temporally and spatially independent, but did not meet the prerequisite assumption of von Mises distribution (Watson's U2 test; $\mathrm{U} 2=2.65, p<0.005$ ), we used the non-parametric MardiaWatson-Wheeler test (Mardia, 1972) with angle as a dependent variables and either species or release habitat as the independent variable. We ran the analyses under an axial (orientation) model. Specifically, we computed the biostatistical analyses using SPSS v 21.0 (IBM Corp., Armonk, USA) while the circular statistics were conducted under PAST v 3.17 (Hammer et al., 2001).

\section{RESULTS}

\section{Brumation Field Observations}

The field surveys during the brumation period highlighted a clear difference in habitat preference between the two treefrog species: during brumation, D. suweonensis was present at rice paddies only while $D$. japonicus occurred at both rice paddies and forests (Figure 3). However, D. japonicus was present in rice paddies until the last week of September only, after which the species was only seen in forests. Neither species was detectable by spotlight transects from the last week of October, temporally matching with the first freeze. The results of the repeated-measure ANOVA 


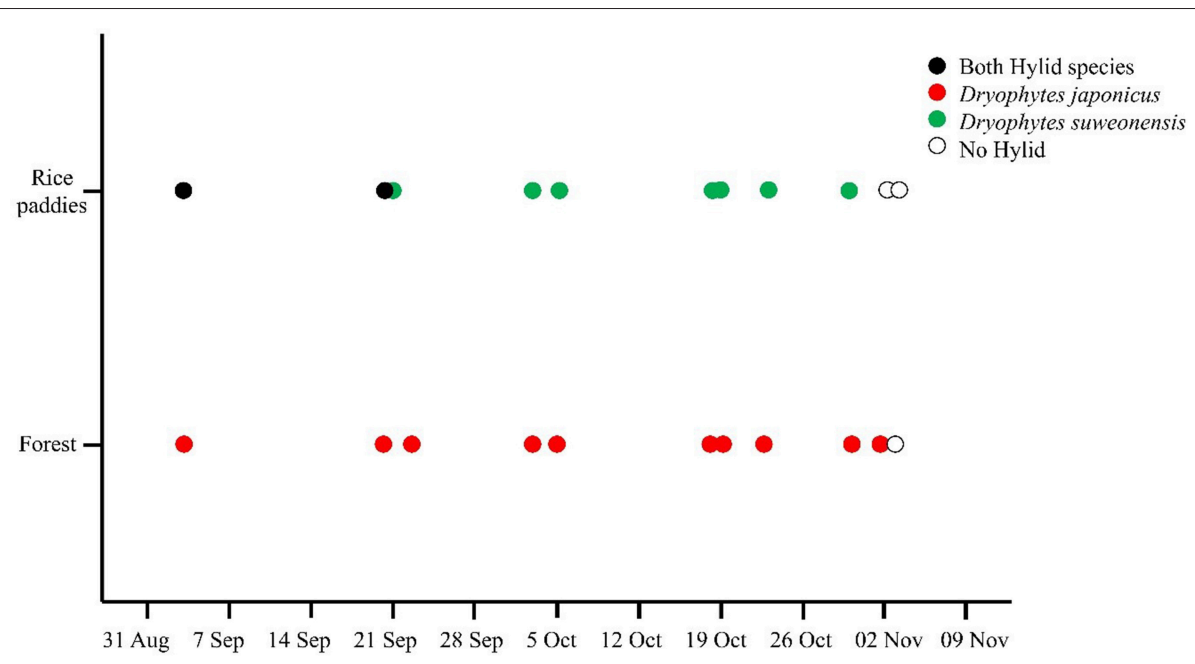

FIGURE 3 | Differences in habitat use by the two Dryophytes species during the brumation period as recorded during field observations (1) at two localities in 2014 ( $n$ $=29$ ) and four localities in $2015(n=32)$. Dryophytes japonicus is present at both rice paddies and forests until late September, before habitat preferences diverged between the two species.

( $n=61)$ supported these results, showing that the occurrence of D. suweonensis significantly varied with season $\left(\chi^{2}=0.64, d=\right.$ $6, p<0.001)$, and $D$. japonicus followed the same pattern $\left(\chi^{2}=\right.$ $0.58, d=6, p<0.001)$. Thus, our results highlight a significant variation in habitat use: both species were present in rice paddies at the beginning of the surveys, whereas $D$. suweonensis was in the rice paddies and $D$. japonicus was in the forests only during the week preceding hibernation.

\section{Field Orientation Tracking for Brumation}

During the fall tracking (2) experiment for D. japonicus in 2013, there was a clear directionality pattern. The species moved away from the rice paddies in $63.6 \%$ of cases $(n=$ $96)$, and toward the forest in $66.2 \%$ of cases $(n=100)$, while moving toward paddies in $36.4 \%$ of cases $(n=55)$, and away from forests in $33.8 \%$ of cases $(n=51)$. Here, away from paddy and toward forest conveys the same directionality vector, but the percentages do not equal $100 \%$ if combined two by two because the directionality is divided into vectors that can have multiple constituents. The logistic regression model was statistically significant, $\chi_{(1)}^{2}=8.38, p=0.004$ and the model explained 78.0\% (Nagelkerke pseudo- $R^{2}$ ) of the variance in directionality and correctly classified $58.9 \%$ of cases.

Dryophytes japonicus used the grass and bush microhabitats to move toward paddies in $1.8 \%$ of cases $(n=3)$ and while they used the rice microhabitat in $96.4 \%$ of cases $(n=146)$. Most movements toward forests were also made in rice $(94 \% ; n=$ 142 ), while remaining movements toward forest were in grass $(4 \% ; n=6)$ and bush $(2 \% ; n=3)$. The distances traveled in relation to directionality were also significantly different between the two species (Table 1; Figure 4), with an average distance moved toward the rice paddies of $48.10 \pm 7.8 \mathrm{~cm}$ and an average distance moved toward the forest of $99.4 \pm 11.2 \mathrm{~cm}$. ID, day,
TABLE 1 | GLM to test the relationships between directionality and other factors collected during the tracking experiment to investigate the brumation behavior of Dryophytes japonicus.

\begin{tabular}{|c|c|c|c|c|c|c|}
\hline & & $\begin{array}{c}\text { Type } \\
\text { III- } \Sigma \chi^{2}\end{array}$ & $d f$ & $\chi^{2}$ & $\boldsymbol{F}$ & $\begin{array}{c}p- \\
\text { value }\end{array}$ \\
\hline \multirow{2}{*}{$\begin{array}{l}\text { Distance } \\
\text { traveled }\end{array}$} & Hypothesis & 13.95 & 24 & 0.58 & 30.47 & 0.032 \\
\hline & Error & 0.04 & 2 & 0.02 & & \\
\hline \multirow[t]{2}{*}{ Individual ID } & Hypothesis & 1.84 & 8 & 0.23 & 12.09 & 0.079 \\
\hline & Error & 0.04 & 2 & 0.02 & & \\
\hline \multirow[t]{2}{*}{ Day } & Hypothesis & 0.52 & 2 & 0.26 & 13.52 & 0.069 \\
\hline & Error & 0.04 & 2 & 0.02 & & \\
\hline \multirow[t]{2}{*}{ Time } & Hypothesis & 16.90 & 100 & 0.17 & 8.86 & 0.107 \\
\hline & Error & 0.04 & 2 & 0.02 & & \\
\hline \multirow[t]{2}{*}{ Habitat } & Hypothesis & 0.39 & 1 & 0.39 & 20.69 & 0.045 \\
\hline & Error & 0.04 & 2 & 0.02 & & \\
\hline \multirow[t]{2}{*}{ Temperature } & Hypothesis & 0.03 & 1 & 0.03 & 1.83 & 0.309 \\
\hline & Error & 0.04 & 2 & 0.02 & & \\
\hline \multirow[t]{2}{*}{ Luminosity } & Hypothesis & 0.01 & 1 & 0.01 & 0.48 & 0.559 \\
\hline & Error & 0.04 & 2 & 0.02 & & \\
\hline
\end{tabular}

time of day, temperature, and luminosity were not significant to directionality (Table 1).

During the fall tracking experiment (2) for D. suweonensis in 2015, there was no clear difference in directionality, in contrast with D. japonicus (Figure 4). The species moved away from the rice paddies in $3.0 \%$ of cases $(n=9)$ but toward paddies in $41.14 \%$ of cases $(n=125)$, and moved away from forests in $20.4 \%$ of cases $(n=62)$ and toward forests in $16.4 \%$ of cases $(n=50)$. The percentages do not equal $100 \%$ if combined two by two because the directionality is divided into vectors that can have multiple constituents. Once tested statistically, the logistic regression model was not significant, $\chi_{(1)}^{2}=0.56$, 


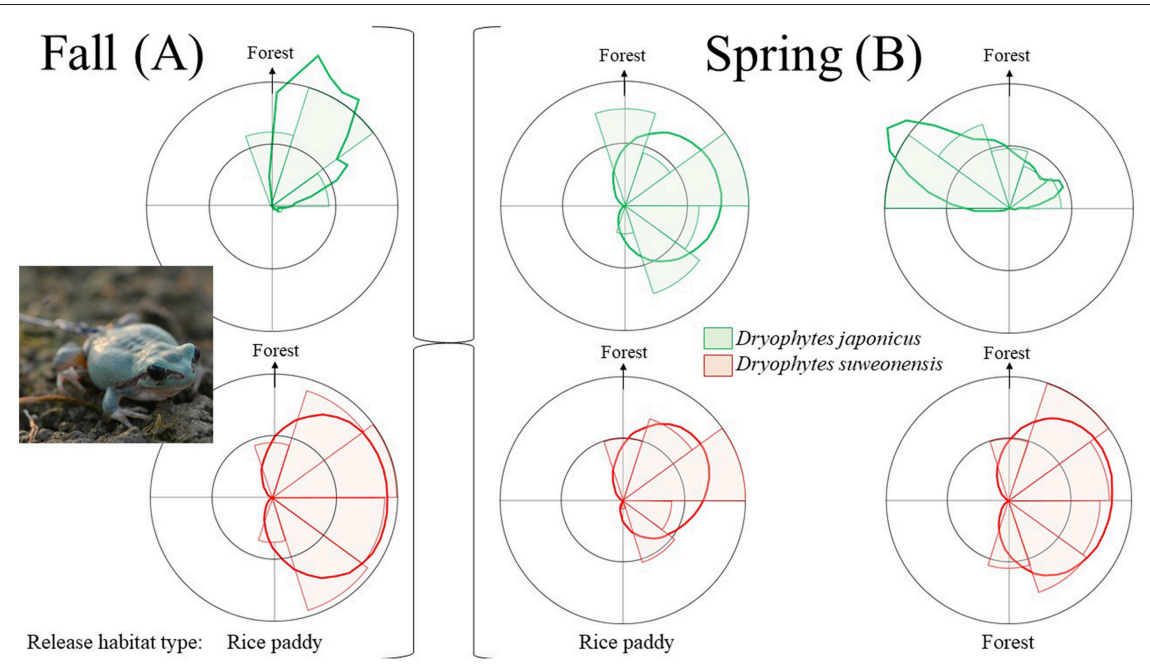

FIGURE 4 | Orientation of the paths taken by Dryophytes japonicus individuals (green) and D. suweonensis individuals (red) during the fall tracking experiment (A) corrected for release point for each individual. Dryophytes japonicus individuals were directed toward forests in $66.2 \%$ of cases, and D. suweonensis individuals moved toward rice paddies in $41.14 \%$ of cases and toward forests in $16.4 \%$ of cases. Rose diagrams show variation in the angles of displacement between Dryophytes japonicus and D. suweonensis in relation to the release habitats (rice paddies or forest; B). The differences in the angles of displacement are significantly different between the two types of environments for both species. The dark lines are kernel density estimates representative of the weighted relative directionality to forest, and the light shaded areas are abundances proportional to radius. For the analyses, direction to forest was used as 0 degrees, and is thus indicated at the top of each rose diagram.

$p=0.453$, explaining $0.1 \%$ (Nagelkerke pseudo- $\mathrm{R}^{2}$ ) of the variance in directionality and correctly classified $55.4 \%$ of cases. There was thus a difference between the two species, with $D$. japonicus displaying a significant preferential direction whereas D. suweonensis did not.

The results of the GLM explaining the factors related to directionality show that only the distance traveled was significant (Table 2). Despite the different distances to forest at the four sites $(139,1018,470$, and $404 \mathrm{~m})$, no significant variation among sites were reported, and it was the same for the variation between individuals, highlighting a general behavior (Table 2). The average distance moved toward the rice paddies between two locations was $78.75 \pm 235.98 \mathrm{~cm}$ while the distance traveled toward the forest was on average $-38.18 \pm 219.34$.

We found a difference in directionality through angles of displacement for the two species in that the angle described by the movements of $D$. japonicus deviated from the forest by 34.79 \pm 5.09 (mean \pm kappa) degrees only on average, whereas the angle described by $D$. suweonensis was $87.55 \pm 1.79$ degrees away from the forest on average (Figure 4). We found the difference in directionality between the two species to be significant (MardiaWatson-Wheeler test; $W=461.80, n=288, p<0.001$ ).

\section{Laboratory Brumation and Hibernation Observations \\ Brumation}

During the brumation period, we observed a significant difference in microhabitat use between the two species (Table 3) under a significant model $\left(\chi^{2}=3266, d f=\right.$ 212, $p<0.001$ ), explaining $85.9 \%$ of variation (Nagelkerke
TABLE 2 | GLM to test the relationships between directionality and other factors collected during the tracking experiment to investigate the brumation behavior of Dryophytes suweonensis.

\begin{tabular}{|c|c|c|c|c|c|c|}
\hline & & $\begin{array}{c}\text { Type } \\
\text { III- } \Sigma \chi^{2}\end{array}$ & $d f$ & $\chi^{2}$ & $F$ & $P$-value \\
\hline \multirow{2}{*}{$\begin{array}{l}\text { Distance } \\
\text { traveled }\end{array}$} & Hypothesis & 115.53 & 75 & 1.54 & 9.53 & $<0.001$ \\
\hline & Error & 34.42 & 213 & 0.16 & & \\
\hline \multirow[t]{2}{*}{ Site } & Hypothesis & 0.39 & 2 & 0.19 & 1.19 & 0.306 \\
\hline & Error & 34.42 & 213 & 0.16 & & \\
\hline \multirow[t]{2}{*}{ Sex } & Hypothesis & 0.02 & 1 & 0.02 & 0.15 & 0.700 \\
\hline & Error & 34.42 & 213 & 0.16 & & \\
\hline \multirow[t]{2}{*}{ Vegetation } & Hypothesis & 0.61 & 3 & 0.20 & 1.27 & 0.286 \\
\hline & Error & 34.42 & 213 & 0.16 & & \\
\hline \multirow[t]{2}{*}{ Date } & Hypothesis & 0.29 & 1 & 0.29 & 1.80 & 0.181 \\
\hline & Error & 34.42 & 213 & 0.16 & & \\
\hline \multirow[t]{2}{*}{ Time } & Hypothesis & 0.21 & 1 & 0.21 & 1.29 & 0.258 \\
\hline & Error & 34.42 & 213 & 0.16 & & \\
\hline \multirow[t]{2}{*}{ Temperature } & Hypothesis & 0.18 & 1 & 0.18 & 1.14 & 0.286 \\
\hline & Error & 34.42 & 213 & 0.16 & & \\
\hline \multirow[t]{2}{*}{ Height } & Hypothesis & 0.02 & 1 & 0.02 & 0.10 & 0.750 \\
\hline & Error & 34.42 & 213 & 0.16 & & \\
\hline \multirow[t]{2}{*}{ Lux } & Hypothesis & 0.03 & 1 & 0.03 & 0.18 & 0.668 \\
\hline & Error & 34.42 & 213 & 0.16 & & \\
\hline \multirow[t]{2}{*}{ Individual ID } & Hypothesis & 0.05 & 1 & 0.05 & 0.33 & 0.568 \\
\hline & Error & 34.42 & 213 & 0.16 & & \\
\hline
\end{tabular}

pseudo- $\left.R^{2}\right)$. Dryophytes japonicus preferentially selected the wood microhabitat $(20.0 \%$ use in D. japonicus and $10.0 \%$ in $D$. suweonensis), whereas $D$. suweonensis preferentially selected the ground microhabitat $(24.0 \%$ use in D. suweonensis and $12.6 \%$ use in D. japonicus; Figure 5). These microhabitats were the most 
commonly used ones after removing the "glass" microhabitat used for displacements (37\% in D. japonicus and $34.0 \%$ in D. suweonensis).

One of the other siignificant differences between the two species was the height at which the frogs were found in the terraria (Table 3). Dryophytes japonicus was on average 23.14 $\pm 4.33 \mathrm{~cm}$ high, whereas $D$. suweonensis was on average 20.37 $\pm 7.37 \mathrm{~cm}$ high. In addition, there was a significant difference between individuals and families, and the model for this analysis was significant $\left(\chi^{2}=373.48, F=264.41, p<0.001\right)$.

\section{Hibernation}

During the hibernation period, the variables microhabitat and height were also significantly different between the two species (Table 4), under a significant model $\left(\chi^{2}=2138.21, d f=232\right.$, $p<0.001$ ) that explained $79.1 \%$ of the variation (Nagelkerke

TABLE 3 | Results of the multinomial logistic regression to investigate variation in microhabitat use between the two species during the brumation experiment ( $n$ $=2,055)$.

\begin{tabular}{lccc}
\hline & $\chi^{\mathbf{2}}$ & $\boldsymbol{d f}$ & $\boldsymbol{P}$-value \\
\hline Species & 30.53 & 16 & $<0.001$ \\
Family & 59.45 & 16 & $<0.001$ \\
ID(Family) & 514.65 & 176 & $<0.001$ \\
Temperature & 13.42 & 4 & 0.009 \\
Height & 2260.70 & 4 & $<0.001$ \\
Time & 5.62 & 4 & 0.229 \\
Date & 44.35 & 4 & $<0.001$
\end{tabular}

pseudo- $R^{2}$ ). In this second phase of the experiment, the use of the flooded microhabitat was higher for D. japonicus (5.7\%) than for D. suweonensis (1.7\%) while D. japonicus moved about twice more than $D$. suweonensis, as seen by the greater use of glass walls (12.9 vs. 6.9\%; Figure 5).

According to the results of the brumation experiment, the heights at which individuals were found was also significantly different (Table 4), with $D$. japonicus again higher on average $(7.19 \pm 9.47 \mathrm{~cm})$ than $D$. suweonensis $(5.21 \pm 8.10 \mathrm{~cm})$. Besides, there was a significant difference between families. The model for this analysis was also significant $\left(\chi^{2}=463.33, F=663.08\right.$, $p$-value $<0.001)$.

\section{Difference Between Brumation and Hibernation}

The multinomial logistic regression to assess whether the two species differed in microhabitat use between brumation and hibernation were significant for species $\left(\chi^{2}=44.83, d f=4, p\right.$ $<0.001)$, phase $\left(\chi^{2}=118.27, d f=4, p<0.001\right)$ and height $\left(\chi^{2}=4362.12, d f=4, p<0.001\right)$. The model was significant $\left(\chi^{2}=5069.81, d f=12, p<0.001\right)$ and explained $78.9 \%$ of the variance (Nagelkerke preudo- $R^{2}$ ). As seen earlier, the frequency of use for the wood microhabitat decreased between the two species between brumation and hibernation, while the frequency increased for the use of the ground microhabitat (Figure 5). The average height also decreased for the two species during the same period.

\section{Winter Field Observations}

Out of the $4 \mathrm{~h}$ spent digging at each of the sites, we found a single individual, a female $D$. suweonensis at the paddy site in Sihung (site $1 ; 37.410046^{\circ} \mathrm{N} ; 126.808053^{\circ} \mathrm{E}$; Figure 2 ). We found

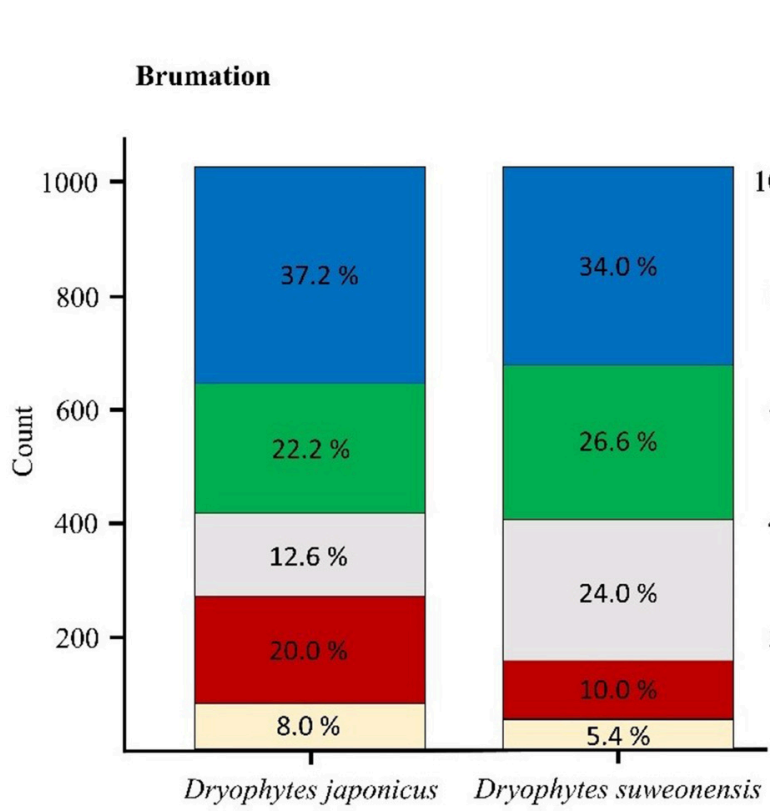

\section{Hibernation \\ (1)}
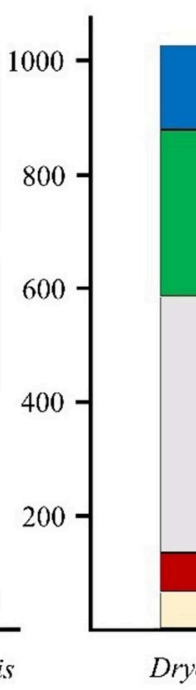

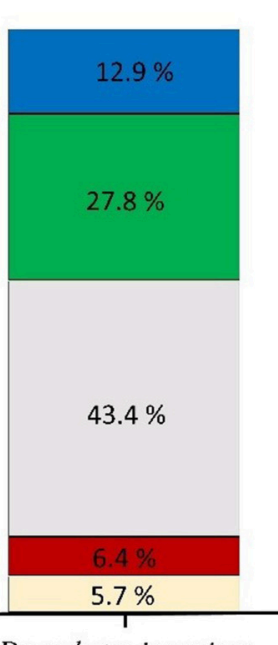

Dryophytes japonicus Dryophytes suweonensis

FIGURE 5 | Microhabitat variation displayed by Dryophytes suweonensis and D. japonicus during brumation and hibernation with corresponding frequency. The variation in the total number of counts was due to the death of three individual $D$. suweonensis during the period before hibernations. The non-annotated stack "pot in water" for $D$. suweonensis is $1.7 \%$. 
TABLE 4 | Results of the multinomial logistic regression to investigate variation in microhabitat use between the two species during the hibernation experiment $(n=1,750)$

\begin{tabular}{lccc}
\hline & $\boldsymbol{\chi}^{\mathbf{2}}$ & $\boldsymbol{d f}$ & $\boldsymbol{P}$-value \\
\hline Species & 34.06 & 4 & $<0.001$ \\
Family & 72.05 & 16 & $<0.001$ \\
ID (Family) & 258.58 & 196 & 0.002 \\
Temperature & 16.80 & 4 & 0.110 \\
Height & 1738.50 & 4 & $<0.001$ \\
Time & 2.72 & 4 & 0.606 \\
Date & 3.51 & 4 & 0.045 \\
\hline
\end{tabular}

TABLE 5 | Results of the GLM to test the factors of importance between the two species during the spring tracking experiment.

\begin{tabular}{lccccc}
\hline & Type III- $\boldsymbol{\Sigma} \boldsymbol{\chi}^{\mathbf{2}}$ & $\boldsymbol{d} \boldsymbol{f}$ & $\boldsymbol{\chi}^{\mathbf{2}}$ & $\boldsymbol{F}$ & $\boldsymbol{P}$-value \\
\hline Species & 1.14 & 1 & 1.14 & 4.25 & 0.040 \\
ID & 7.22 & 24 & 0.30 & 1.12 & 0.309 \\
Habitat & 5.66 & 4 & 1.41 & 5.29 & 0.000 \\
Date & 0.28 & 1 & 0.28 & 1.06 & 0.304 \\
Time & 0.11 & 1 & 0.11 & 0.40 & 0.527 \\
Temp & 0.07 & 1 & 0.07 & 0.26 & 0.610 \\
Height & 0.04 & 1 & 0.04 & 0.16 & 0.686 \\
Error & 224.48 & 839 & 0.27 & & \\
\hline
\end{tabular}

the individual in a burrow excavated by an unknown animal. The individual was buried between 27 and $30 \mathrm{~cm}$ deep. The absence of other findings does not reflect the absence of individuals, but only our inability to find them.

\section{Spring Orientation Tracking}

The directionality exhibited by D. japonicus and D. suweonensis during the spring tracking experiment was significantly different between the two species (Table 5). When released in the forest habitat, $60.1 \%$ of $D$. japonicus displacements were away from the forest release point, and $42.6 \%$ toward rice paddies (Table 6), a significant difference between the two directions for the species ( $T$-test; $t=-8.15, d f=127, p<0.001$ ). In contrast, there was no difference in directionality between the two species when released in the rice paddies (Table 6; $T$-test; $t=-1.31$, $d f=$ $45, p=0.198)$. Oppositely, the movements of $D$. suweonensis toward and away from the forest when released in that habitat were not significantly different (Table 6; $T$-test; $t=-3.49, d f=$ $50, p=0.186)$, neither than it was significant when released in rice paddies (Table 6; T-test; $t=-0.32, d f=46, p=0.749$; Figure 4). This pattern was the same for the cumulated distances traveled by the two species toward either rice paddies (D. japonicus $=20.60$ \pm 128.62 and $D$. suweonensis $=15.82 \pm 119.01 \mathrm{~m}$; ANOVA; $\chi^{2}$ $\left.=402.09, F_{(1,872)}=0.07, p=0.786\right)$ or forests $[D$. japonicus $=$ $-30.46 \pm 119.36$ and $D$. suweonensis $0.98 \pm 115.80$; ANOVA; $\chi^{2}$ $=31439.84, F_{(1,872)}=6.61, p=0.010$; here cumulated by type of site for ease of understanding].
TABLE 6 | Descriptive statistics for the directionality of the movements exhibited by Dryophytes suweonensis and $D$. japonicus in relation to the type of site selected for the release (i.e., rice paddy or forest) during the spring tracking experiments.

\begin{tabular}{lcc}
\hline Habitat & \multicolumn{2}{c}{ Species } \\
\cline { 2 - 3 } Forest & D. japonicus & D. suweonensis \\
\hline DIRECTIONALITY IN RELATION TO FOREST & 56.7 \\
Away from forest & 60.1 & 43.3 \\
Toward forest & 13.9 & \\
DIRECTIONALITY IN RELATION TO PADDY & & 22.4 \\
Away from paddy & 15.9 & 77.6 \\
Toward paddy & 46.2 & \\
Paddy & & 45.5 \\
DIRECTIONALITY IN RELATION TO FOREST & 54.5 \\
Away from forest & 50.9 & \\
Toward forest & 49.1 & 40.0 \\
DIRECTIONALITY IN RELATION TO PADDY & & 60.0 \\
Away from paddy & 40.4 & \\
Toward paddy & 59.6 & \\
\hline
\end{tabular}

Data pooled two-by-two do not equal $100 \%$ because frogs were sometimes immobile and thus did not provide any directionality data for a few hours.

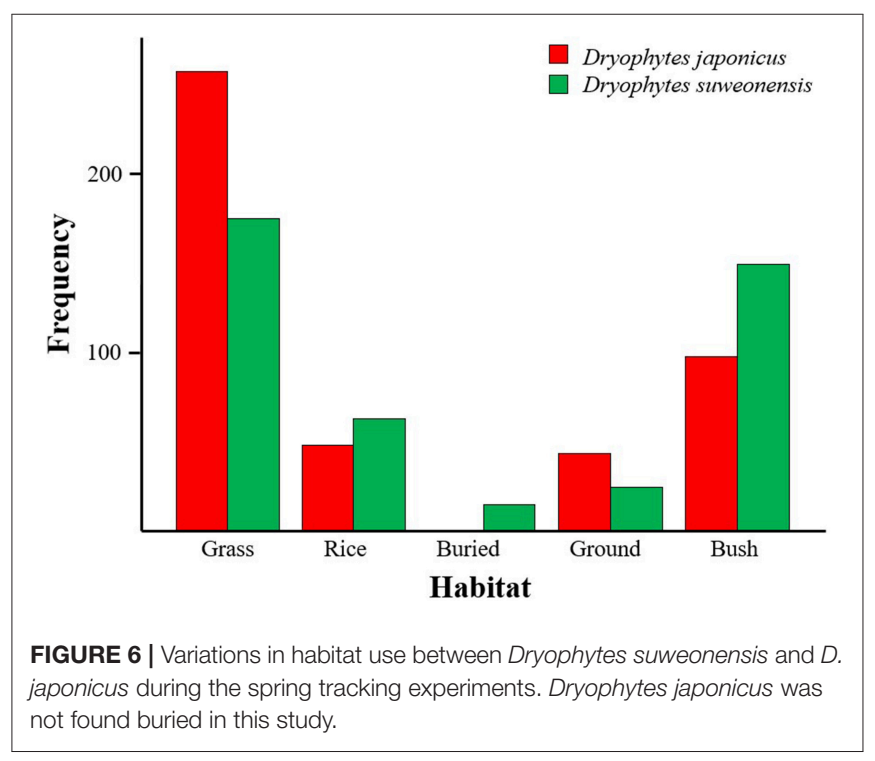

The results of the first GLM also showed a difference in microhabitat use between the two species (Table 5), with grass preferentially used by D. japonicus, and grass and bush principally used by $D$. suweonensis. However, we never found D. japonicus buried, and we found D. suweonensis buried in only $3.3 \%$ of cases and on the bare ground in only $6.3 \%$ of cases (Figure 6).

When assessing the difference in directionality for the two species (Figure 7), the angles were significantly different (Mardia-Watson-Wheeler tests) when released in rice paddies [D. japonicus: $79.22 \pm 1.69$ (mean \pm kappa); D. suweonensis: $68.02 \pm 2.00]$, and forests (D. japonicus: $113.77 \pm 1.87$; 
D. suweonensis: $86.39 \pm 1.57)$. In addition, the variables were significantly different (Mardia-Watson-Wheeler tests) for: habitat of release for both $D$. japonicus ( $W=364.76, n=225, p<$ 0.001 ) and $D$. suweonensis ( $W=326.79, n=221, p<0.001)$ but also between both species for a given release habitat: rice paddies $(W=306.23, n=192, p<0.001)$ and forests $(W=387.23, n=$ $245, p<0.001)$.

\section{DISCUSSION}

Extensively different traits can occur with little genetic change (West-Eberhard, 2005), and here we further developed the suspected divergence in evolutionary history between the two Korean species of Dryophytes treefrogs (Ham, 2014; Kim, 2016). Whereas, $D$. japonicus migrates twice yearly between rice paddies and forested areas, to breed and overwinter, D. suweonensis is present at rice paddies all year round and hibernates buried underground. The ancestors of the two species diverged during the Late Miocene (8.7 6.5 Mya Duellman et al., 2016; Dufresnes et al., 2016), apparently when one of the two species adapted to a different environment. It is likely that this happened when $D$. suweonensis preferentially selected marshes for breeding, whereas the preference of the ancestral species is expected to have been broader, a characteristic shared by most Hyla and Dryophytes species. Breeding in a different habitat led to the acquisition of new behavioral traits, such as holding on vegetation while calling (Borzée et al., 2016a), but also to the loss of traits, here migration. It is unlikely that the seasonal migration is a newly acquired trait in D. japonicus given that the species breeds in most types of habitats, also at higher elevations (Roh et al., 2014), and thus migration is expected to have been the ancestral character. The migration distance may, however, have been modified by the development of agriculture, with the two species brought back into contact (Borzée et al., 2015b, 2017a). Dryophytes suweonensis breeding in a separate habitat is the preferred hypothesis as this scenario enables the development of pre-zygotic isolating traits, such as seen in Dryophytes cinereus (Höbel and Gerhardt, 2003), and the two species are able to hybridize (Kuramoto, 1984; Borzée et al., 2015b), and have thus not evolved post-zygotic isolation. Sympatric speciation is hypothesized as peri- and para-patric speciations cannot have occurred with the two species displaying sympatric ranges (Jang et al., 2011).

During the breeding season, both species call from rice paddies, and although calling is discontinued in early July (Roh et al., 2014), both species are present in the vicinity of rice paddies until mid-September, where individuals sometimes produce calls. Continued vocalizations are unlikely to be for mating purposes because juveniles attempt the same behavior in synchrony (Pers. Obs.). At this point in time, adult D. japonicus migrate toward forests, up to several hundred meters away in this study, although closely related species can migrate up to $8 \mathrm{~km}$ (Angelone and Holderegger, 2009). Males D. japonicus will be present on the tree canopy, favoring oak trees (Borzée et al., 2018c) and producing calls as observed during transects here, until they are not seen anymore, in late October/early November, temporally coinciding with the first frost. Adult and juvenile D. suweonensis stay in

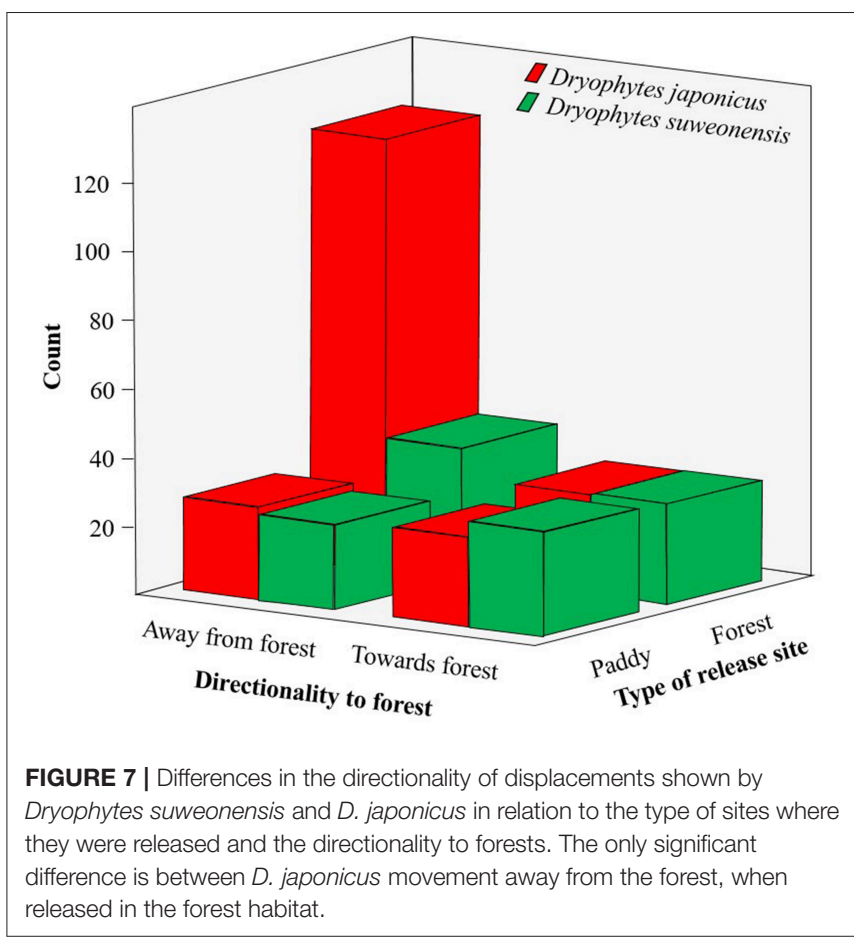

the vicinity of rice paddies, favoring the upper leaves of planted beans (Borzée and Jang, 2017), hypothetically for feeding based on the high insect density seen in proximity. This, however, also makes the species susceptible to the bean harvest, which potentially affects recruiting young individuals into the breeding pool (Borzée and Jang, 2017). Individuals will then find shelter underground on the banks of rice paddies, where rice straw is stacked after harvest but also burnt before the thaw of ice, with unknown consequences for the species.

Both before and after overwintering, the two species displayed variations in the orientation of their displacements in relation to forests and rice paddies. Dryophytes japonicus was aiming at forested hills before winter, whereas D. suweonensis displayed non-directional displacements. After winter, the difference between the species was still present, with $D$. japonicus moving toward the breeding sites when released in the forest, whereas D. suweonensis did not display any directionality. It would seem that $D$. suweonensis was unable to find its way toward the breeding sites. When released in rice paddies, both of the species displayed non-directional displacements, an indication that they had reached their target sites, for breeding and feeding (Kim, 2015a), and that the directionality D. japonicus displayed toward forests before hibernation and toward rice paddies afterwards was not an artifact. Our results raise an interesting question regarding the methods used to display directionality. Amphibian species are known to rely on a set of methods to orientate their movement (see review by (Sinsch, 1990)). However, because all individuals had been kept in laboratory for a month prior to release, or were laboratory born, landscape and field recognition could not be learned. Also, rainy conditions during the fall orientation experiment reduced the possibility of celestial navigation or the use of polarized light. 
The behavior expressed by the two species while they were kept in terraria during fall and winter differed clearly between species and between seasons following what would have been expected from wild individuals. During brumation, D. suweonensis was found on the ground of the terraria, whereas we found $D$. japonicus more often on wooden structures, at higher heights from the ground. The difference in height matches the brumating behavior we recorded in the wild, with $D$. suweonensis brumating in the vicinity of rice paddies, that is, in areas without high vertical structures, whereas D. japonicus is found on trees most of the time. The preference for bean leaves by $D$. suweonensis in the wild, around $50 \mathrm{~cm}$ high, may thus be more closely related to prey availability than microhabitat preference. The hibernation period saw the two species exploiting the ground microhabitat, and thus hints at the use of buried hibernacula for hibernating by the two species. Dryophytes japonicus was more active and was found higher up during the period, in agreement with the high freeze tolerance shown by the species (Storey and Storey, 2017).

Amphibian populations have greatly declined in recent decades (Blaustein et al., 1994), with approximately one third of all species currently under threat of extinction and more than 200 species already extinct (Hayes et al., 2002). The potential for extinctions in pristine environments such as Madagascar (Kolby, 2014) is still high, and basic ecological knowledge is still required for a high number of amphibians, as highlighted by the Data Deficient designation of species by the IUCN (International Union for Conservation of Nature) on its Red List of endangered species. In response to these losses, biodiversity conservation efforts have been deployed to tackle population decreases and extinctions (Marsh and Trenham, 2001; Gascon, 2007). However, and especially with amphibians, most conservation work is addressed to the breeding habitat, and thus, not all conservation efforts have been successful (Blaustein and Kiesecker, 2002). Failure is not necessarily attributable to the work carried out but because of limiting factors such as basic knowledge. We therefore urge the implementation of conservation measures for D. suweonensis, listed as endangered by the IUCN (IUCN,

\section{REFERENCES}

Able, K. P., and Able, M. A. (1995). Interactions in the flexible orientation system of a migratory bird. Nature 375:230. doi: 10.1038/ 375230a0

Angelone, S., Holderegger, R. (2009). Population genetics suggests effectiveness of habitat connectivity measures for the European tree frog in Switzerland. J. Appl. Ecol. 46, 879-87. doi: 10.1111/j.1365-2664.2009.01670.x

Atkins, K. E., and Travis, J. M. (2010). Local adaptation and the evolution of species' ranges under climate change. J. Theor. Biol. 266, 449-457. doi: 10.1016/j.jtbi.2010.07.014

Baldwin, R. F., Calhoun, A. J., and deMaynadier, P. G. (2006). Conservation planning for amphibian species with complex habitat requirements: a case study using movements and habitat selection of the wood frog Rana sylvatica. J. Herpetol. 40, 442-453. doi: 10.1670/0022-1511(2006)40[442:CPFASW]2.0. $\mathrm{CO} ; 2$

Balogová, M., Jelić, D., Kyselová, M., and Uhrin, M. (2017). Subterranean systems provide a suitable overwintering habitat for Salamandra salamandra. Int. J. Speleol. 46, 321-329. doi: 10.5038/1827-806X.46.3.2026
2018) and under Korean law (Ministry of Environment, 2012), highlighting that protecting the totality of the space used by the species is easier than for most species, as hibernation and breeding habitats overlap. Despite the areas to protect being only in rice paddies, international conservation plans such as the ones developed under the Ramsar convention will meet the dual objective.

\section{AUTHOR CONTRIBUTIONS}

$\mathrm{AB}$ designed the experiment, collected and analyzed the data and wrote the manuscript. YC analyzed data and participated in writing. YK collected data and participated in writing. PJ supervised. YJ designed the experiment, revised the manuscript, and supervised the project.

\section{FUNDING}

Our work was financially supported by a grant from the National Geographic Society Asia (Young Explorer \#17-15), two Small Grants for Science and Conservation from The Biodiversity Foundation (2015 and 2016) to AB; a grant from Korea Environmental Industry \& Technology Institute (KEITI RE201709001), a grant from the Korea Rural Community Corporation for the translocation of the Suweon treefrog individuals, a grant from the National Geographic Asia (\#2-2016-1632-001-1), a grant (\#PJ01228503) by the Rural Development Administration of Korea, a research grant (\#2017R1A2B2003579) by the National Research Foundation of Korea to YJ; and by the BK21 program at the School of Biological Sciences.

\section{ACKNOWLEDGMENTS}

We apologize for difficulties encountered by color-blind readers and recommend printing the figures in shades of gray for easier understanding. We are grateful to Minwha Hong, Yeongseon Park, Miyeon Kim, Junyung Kim, and Taeho Kim for their help rearing and tracking the frogs.
Beach, F. A. (1961). Hormones and Behavior. New York, NY: Cooper Square.

Benvenuti, S., Dall'Antonia, P., and Ioalè, P. (1996). Directional preferences in the autumn migration of the red admiral (Vanessa atalanta). Ethology 102, 177-186. doi: 10.1111/j.1439-0310.1996.tb01116.x

Berman, D. I., Meshcheryakova, E. N., and Bulakhova, N. A. (2016). The Japanese tree frog (Hyla japonica), one of the most cold-resistant species of amphibians. Doklady Biol. Sci. 471, 276-279. doi: 10.1134/S001249661 6060065

Blaustein, A. R., and Kiesecker, J. M. (2002). Complexity in conservation: lessons from the global decline of amphibian populations. Ecol. Lett. 5, 597-608. doi: 10.1046/j.1461-0248.2002.00352.x

Blaustein, A. R., Wake, D. B., Sousa, W. P. (1994). Amphibian declines: judging stability, persistence, and susceptibility of populations to local and global extinctions. Conserv. Biol. 8, 60-71. doi: 10.1046/j.1523-1739.1994. 08010060.x

Borzée, A. (2018). Why are Anurans Threatened? The Case of Dryophytes Suweonensis. Ph.D. Seoul National University, School of Biological Science.

Borzée, A., Ahn, J., Kim, S., Heo, K., and Jang, Y. (2015a). Seoul, keep your paddies! Implications for the conservation of hylid species. 
Animal Syst. Evol. Divers. 31, 176-181. doi: 10.5635/ASED.2015. 31.3.176

Borzée, A., Andersen, D., and Jang, Y. (2018a). Population trend inferred from aural surveys for calling anurans in Korea. PeerJ 6:e5568. doi: $10.7717 /$ peerj. 5568

Borzée, A., Fong, J., and Jang, Y. (2015b). Broad introgression patterns between two Hylid species from the Korean Peninsula: the case of Hyla suweonensis and $H$. japonica. In: Conference of the Korean Research Society of Herpetologists. Wonju.

Borzée, A., Heo, K., and Jang, Y. (2018b). Relationship between agroenvironmental variables and breeding Hylids in rice paddies. Sci. Rep. 8:8049. doi: 10.1038/s41598-018-26222-w

Borzée, A., and Jang, Y. (2015). Description of a seminatural habitat of the endangered Suweon treefrog, Hyla suweonensis. Animal Cells Syst. 19, 1-5. doi: 10.1080/19768354.2015.1028442

Borzée, A., and Jang, Y. (2017). Impact of rice and bean harvests on the Suweon Treefrog (Dryophytes suweonensis). Int J Curr Res. 9, 59620-59623.

Borzée, A., and Jang, Y. (2018). Large-scale hybridisation as an extinction threat to the Suweon treefrog (Dryophytes suweonensis). Conservation Asia 2018 (section SfCBA ed., Vol. 1.) Bishkek: Society for Conservation Biology-Asia section.

Borzée, A., Kim, J. Y., Cunha, M. A., Lee, D., Sin, E., Oh, S., et al. (2016b). Temporal and spatial differentiation in microhabitat use: implications for reproductive isolation and ecological niche specification. Integr. Zool. 11, 375-387. doi: 10.1111/1749-4877.12200

Borzée, A., Kim, J. Y., and Jang, Y. (2016a). Asymmetric competition over calling sites in two closely related treefrog species. Sci. Rep. 6:32569. doi: $10.1038 /$ srep32569

Borzée, A., Kim, K., Heo, K., Jablonski, P. G., and Jang, Y. (2017a). Impact of land reclamation and agricultural water regime on the distribution and conservation status of the endangered Dryophytes suweonensis. PeerJ. 5:e3872. doi: $10.7717 /$ peerj. 3872

Borzée, A., Kim, M., Kim, J. Y., Kim, T., and Jang, Y. (2018c). Microhabitat use during brumation in the Japanese treefrog, Dryophytes japonicus. AmphibiaReptilia 39, 163-175. doi: 10.1163/15685381-17000036

Borzée, A., Kim, Y. I., Kim, K., and Jang, Y. (2018d). Methodological development for HDF tracking in salamanders. Herpetol Conserv Biol. 13, 473-478.

Borzée, A., Kim, Y. I., Kim, Y. E., and Jang, Y. (2018e). Translocation of the endangered and endemic Korean treefrog Dryophytes suweonensis. Conserv Evid. 15, 6-11.

Borzée, A., Kosch, T. A., Kim, M., and Jang, Y. (2017b). Introduced bullfrogs are associated with increased Batrachochytrium dendrobatidis prevalence and reduced occurrence of Korean treefrogs. PLoS ONE 12:e0177860. doi: 10.1371/journal.pone.0177860

Borzée, A., Kyong, C. N., Kil, H. K., and Jang, Y. (2018f). Impact of water quality on the occurrence of two endangered Korean anurans: Dryophytes suweonensis and Pelophylax chosenicus. Herpetologica 74, 1-7. doi: 10.1655/Herpetologica-D-17-00011

Borzée, A., Park, S., Kim, A., Kim, H.-T., and Jang, Y. (2013). Morphometrics of two sympatric species of tree frogs in Korea: a morphological key for the critically endangered Hyla suweonensis in relation to H. japonica. Animal Cells Syst. 17, 348-356. doi: 10.1080/19768354.2013.842931

Borzée, A., and Seliger, B. (2018). Dryophytes suweonensis (Suweon Treefrog). Herpetol. Rev. Geogr. Distrib. 49:707.

Borzée, A., Yu, A.-Y., and Jang, Y. (2018g). Variations in boldness, behavioural and physiological traits of an endangered and a common hylid species from Korea. Ethol Ecol Evol. 30, 515-533. doi: 10.1080/03949370.2018.1441192

Box, G. E., and Tidwell, P. W. (1962). Transformation of the independent variables. Technometrics 4, 531-550. doi: 10.1080/00401706.1962.104 90038

Brower, L. P. (1995). Understanding and misunderstanding the migration of the monarch butterfly(Nymphalidae) in North America: 1857-1995. J. Lepidopterists Soc. 49, 304-385.

Catenazzi, A. (2016). Ecological implications of metabolic compensation at low temperatures in salamanders. PeerJ 4:e2072. doi: $10.7717 /$ peerj. 2072
Cayuela, H., Valenzuela-Sanchez, A., Teulier, L., Martínez-Solano, Í., Léna, J., Merilä, J., et al. (2018). Determinants and consequences of dispersal in vertebrates with complex life cycles: a review of pond-breeding amphibians. PeerJ 6:e27394. doi: 10.7287/peerj.preprints.27394v1

Chippindale, P. T., Bonett, R. M., Baldwin, A. S., and Wiens, J. J. (2004). Phylogenetic evidence for a major reversal of life-history evolution in plethodontid salamanders. Evolution 58, 2809-2822. doi: 10.1111/j.0014-3820.2004.tb01632.x

Collins, J. P. (1981). Distribution, habitats and life history variation in the tiger salamander, Ambystoma tigrinum, in east-central and southeast Arizona. Copeia 3, 666-675. doi: 10.2307/1444572

de Moura Presa, E., Zürcher, J. F., and Skrivervik, A. K. (2005). A new microwave harmonic direction-finding system for localization of small mobile targets using passive tags. Microwave Optical Technol. Lett. 47, 134-137. doi: $10.1002 /$ mop. 21102

Denton, J., and Beebee, T. (1993). Density-related features of natterjack toad (Bufo calamita) population in Britain. J. Zool. 229, 105-119. doi: 10.1111/j.1469-7998.1993.tb02624.x

Duellman, W., and Trueb, L. (1986). Biology of Amphibians. New York, NY: McGraw-Hill.

Duellman, W. E. (1989). Alternative life-history styles in anuran amphibians: evolutionary and ecological implications. In: Bruton, M. N., editor. Alternative Life-History Styles of Animals. (New York, NY: Springer). p. 101-26. doi: 10.1007/978-94-009-2605-9_6

Duellman, W. E., Marion, A. B., and Hedges, S. B. (2016). Phylogenetics, classification, and biogeography of the treefrogs (Amphibia: Anura: Arboranae). Zootaxa 4104, 1-109. doi: 10.11646/zootaxa.4104.1.1

Dufresnes, C., Litvinchuk, S. N., Borzée, A., Jang, Y., Li, J.-T., Miura, I., et al. (2016). Phylogeography reveals an ancient cryptic radiation in East-Asian tree frogs (Hyla japonica group) and complex relationships between continental and island lineages. BMC Evol. Biol. 16:253. doi: 10.1186/s12862-0160814-x

Elzanowski, A., Ciesiołkiewicz, J., Kaczor, M., Radwanska, J., and Urban, R. (2009). Amphibian road mortality in Europe: a meta-analysis with new data from Poland. Eur. J. Wildlife Res. 55, 33-43. doi: 10.1007/s10344-0080211-x

Emlen, S. T., and Emlen, J. T. (1966). A technique for recording migratory orientation of captive birds. Auk 83, 361-367. doi: 10.2307/40 83048

Eng, M. L., Stutchbury, B. J. M., and Morrissey, C. A. (2017). Imidacloprid and chlorpyrifos insecticides impair migratory ability in a seed-eating songbird. Sci. Rep. 7:15176. doi: 10.1038/s41598-017-15446-x

Feder, M. E., and Burggren, W. W. (1992). Environmental physiology of the amphibians. Chicago, IL: University of Chicago Press.

Gascon, C. (2007). Amphibian conservation action plan: proceedings IUCN/SSC Amphibian Conservation Summit 2005. Gland: IUCN.

Gittins, S. (1983). The breeding migration of the Common toad (Bufo bufo) to a pond in mid-Wales. J. Zool. 199, 555-562. doi: 10.1111/j.1469-7998.1983.tb05106.x

Griffiths, R. (1984). Seasonal behaviour and intrahabitat movements in an urban population of smooth newts, Triturus vulgaris (Amphibia: Salamandridae). J. Zool. 203, 241-251. doi: 10.1111/j.1469-7998.1984.tb02330.x

Groffen, J., Borzée, A., and Jang, Y. (2018). Positioning of two treefrog species within rice paddies in relation to different habitat borders. Anim Cells Syst. 22, 205-221. doi: 10.1080/19768354.2018.1475301

Ham, C.-H. (2014). Morphology, Age Structure and Mating Call Characteristics of Japanese tree frog (Hyla japonica) and Suweon tree frog (Hyla suweonensis). Master Thesis, Chonnam National University, Department of Life Science.

Hammer, Ø., Harper, D. A. T., and Ryan, P. D. (2001). PAST: Paleontological Statistics Software Package for education and data analysis. Palaeontologia Electr. 4:9.

Hayes, T. B., Collins, A., Lee, M., Mendoza, M., Noriega, N., Stuart, A. A., et al. (2002). Hermaphroditic, demasculinized frogs after exposure to the herbicide atrazine at low ecologically relevant doses. Proc. Natl. Acad. Sci. U.S.A. 99, 5476-5480. doi: 10.1073/pnas.082121499

Heino, M., and Godø, O. R. (2002). Fisheries-induced selection pressures in the context of sustainable fisheries. Bull. Mar. Sci. 70, 639-656. 
Höbel, G., and Gerhardt, H. C. (2003). Reproductive character displacement in the acoustic communication system of green tree frogs (Hyla cinerea). Evolution 57, 894-904. doi: 10.1111/j.0014-3820.2003.tb00300.x

Hutchinson, V. H. (1979). "Thermoregulation," in Turtles: Perspectives and Research, eds M. Harless and H. Morlock (New York, NY: John Wiley and Sons), 207-228.

Iangrai, A. J. (2011). Studies on Ecology, Breathing Behaviour and Metamorphosis of Tree Frogs Polypedates Leucomystax and Rhacophorus Bipunctatus (Anura: Rhacophoridae) in Meghalaya (North-East India). Shilling: North Eastern Hill University.

IUCN (2018). Dryophytes suweonensis. Gland: IUCN.

Jang, Y., Hahm, E. H., Lee, H.-J., Park, S., Won, Y.-J., Choe, J. C., et al. (2011). Geographic variation inadvertisement calls in a tree frog species: gene flow and selection hypotheses. PLOS ONE 6:E23297. doi: 10.1371/journal.pone. 0023297

Johnson, J. R., Mahan, R. D., and Semlitsch, R. D. (2008). Seasonal terrestrial microhabitat use by gray treefrogs (Hyla versicolor) in Missouri oak-hickory forests. Herpetologica 64, 259-269. doi: 10.1655/07-064.1

Johnson, S. A. (2003). Orientation and migration distances of a pond-breeding salamander (Notophthalmus perstriatus, Salamandridae). Alytes 21:3.

Kaiser, M. J., and De Groot, S. J. (2000). The Effects of Fishing on Non-Target Species and Habitats: Biological, Conservation and Socio-Economic Issues. Oxford: Blackwell Science.

Kenney, R. D., Mayo, C. A., and Winn, H. E. (2001). Migration and foraging strategies at varying spatial scales in western North Atlantic right whales: a review of hypotheses. J Cetacean Res Manage. 2, 251-260.

Kim, E., Nugraha, C. A., Jang, Y., and Borzée, A. (in press). Home range variation between Korean Hylids (Dryophytes sp.). J Asia-Pacific Biodivers. doi: 10.1016/j.japb.2018.12.002

Kim, J. Y. (2015a). Lekking Behavior in the Japanese Treefrog Hyla japonica. (Seoul: Department of Life Science, Ewha Womans University).

Kim, M. Y. (2015b). Testing Exploitative Competition of Calling Sites Between Sympatric Hylid Species in Korea. Master Thesis, Department of Life Science, Ewha Womans University.

Kim, Y. E. (2016). Differential Antipredator Behavior Between Hyla japonica and H. suweonensis Suggests Separate Evolution. Master Thesis, Ewha Womans University, Department of Life Science.

Kolby, J. E. (2014). Stop Madagascar's toad invasion now. Nat. Corresp. 509:563. doi: $10.1038 / 509563 \mathrm{a}$

Kovar, R., Brabec, M., Vita, R., and Bocek, R. (2009). Spring migration distances of some Central European amphibian species. Amphibia-Reptilia 30, 367-378. doi: $10.1163 / 156853809788795236$

Kundey, S. M. A., Lessard, A., Fitz, A., and Panwar, M. (2018). Tiger salamanders' (Ambystoma tigrinum) response retention and usage of visual cues following brumation. Behav. Process. 157, 502-508. doi: 10.1016/j.beproc.2018.06.008

Kuramoto, M. (1984). Systematic implications of hybridization experiments with some eurasian treefrogs (genus Hyla). Copeia 3, 609-16. doi: 10.2307/ 1445141

Kuzmin, S., Maslova, I., Matsui, M., Liang, F., and Kaneko, Y. (2017). Dryophytes japonicus. Gland: IUCN.

Lee, E., and Moon, S. (2011). Assessment of characteristics and functions of abandoned rice paddy wetlands as habitats for the amphibia within land development districts. J. Korea Soc. Environ. Restor. Technol. 14, 35-42.

Lenhardt, P. P., Brühl, C. A., and Berger, G. (2015). Temporal coincidence of amphibian migration and pesticide applications on arable fields in spring. Basic Appl Ecol. 16, 54-63. doi: 10.1016/j.baae.2014.10.005

Lenhardt, P. P., Schäfer, R. B., Theissinger, K., and Brühl, C. A. (2013). An expert-based landscape permeability model for assessing the impact of agricultural management on amphibian migration. Basic Appl. Ecol. 14, 442-451. doi: 10.1016/j.baae.2013.05.004

Lockhart, R. A., Stephens, M. A. (1985). Tests of fit for the von Mises distribution. Biometrika 72, 647-652. doi: 10.1093/biomet/72.3.647

Macias, D. A., Groffen, J., Jang, Y., and Borzée, A. (2018). Rana coreana (Korean Brown Frog) and R. uenoi (Ueno's Brown Frog). Hibernaculum. Herpetol. Rev. $49,121-122$

Madison, M. (1977). Contributions From the Gray Herbarium. Cambridge, MA: Harvard University Press.
Maeda, N., and Matsui, M. (1993). Frog and Toads of Japan. 3rd Edn. Tokyo: Bun-ichi Sogo Shuppan.

Mahan, R. D., and Johnson, J. R. (2007). Diet of the gray treefrog (Hyla versicolor) in relation to foraging site location. J. Herpetol. 41, 16-23. doi: 10.1670/00221511(2007)41[16:DOTGTH]2.0.CO;2

Mardia, K. V. (1972). A multi-sample uniform scores test on a circle and its parametric competitor. J. R. Stat. Soc. Ser. B. 34, 102-113. doi: 10.1111/j.2517-6161.1972.tb00891.x

Marsh, D. M., and Trenham, P. C. (2001). Metapopulation dynamics and amphibian conservation. Conserv. Biol. 15, 40-9. doi: 10.1111/j.1523-1739.2001.00129.x

Mayhew, W. W. (1968). Biology of desert amphibians and reptiles. In: Brown, G. W., editor. Desert Biology Special Topics on the Physical and Biological Aspects of Arid Regions, Volume 1. New York, NY: Academics. p. 226-229. doi: 10.1016/B978-1-4831-9868-2.50014-1

Mayr, E. (1963). Animal Species and Evolution. Cambridge, MA: Harvard University Press. doi: 10.4159/harvard.9780674865327

McEachern, M. A., Adams, A. A. Y., Klug, P. E., Fitzgerald, L. A., and Reed, R. N. (2015). Brumation of introduced black and white tegus, Tupinambis merianae (Squamata: Teiidae), in Southern Florida. Southeastern Natural. 14, 319-328. doi: $10.1656 / 058.014 .0207$

Miaud, C., Guyétant, R., and Elmberg, J. (1999). Variations in life-history traits in the common frog Rana temporaria (Amphibia: Anura): a literature review and new data from the French Alps. J. Zool. 249, 61-73. doi: 10.1111/j.1469-7998.1999.tb01060.x

Ministry of Environment, R. O. K. (2012). Hyla suweonensis. Available online at: http://www.me.go.kr (Accessed January 30, 2013).

Morrison, C., and Hero, J. M. (2003). Geographic variation in life-history characteristics of amphibians: a review. J. Anim. Ecol. 72, 270-279. doi: 10.1046/j.1365-2656.2003.00696.x

Oring, L. W., Fivizzani, A. J., and El Halawani, M. E. (1986). Changes in plasma prolactin associated with laying and hatch in the spotted sandpiper. Auk $103,820-822$.

Park, S., Jeong, G., and Jang, Y. (2013). No reproductive character displacement in male advertisement signals of Hyla japonica in relation to the sympatric H. suweonensis. Behav. Ecol. Sociobiol. 67, 1345-1355. doi: 10.1007/s00265-013-1563-0

Pašukonis, A., Loretto, M.-C., Landler, L., Ringler, M., and Hödl, W. (2014). Homing trajectories and initial orientation in a Neotropical territorial frog, Allobates femoralis (Dendrobatidae). Front. Zool. 11:29. doi: 10.1186/1742-9994-11-29

Pašukonis, A., Ringler, M., Brandl, H. B., Mangione, R., Ringler, E., and Hödl, W. (2013). The homing frog: high homing performance in a territorial dendrobatid frog (Dendrobatidae). Ethology 119, 762-768. doi: 10.1111/eth.12116

Pellet, J., Rechsteiner, L., Skrivervik, A. K., Zürcher, J.-F., and Perrin, N. (2006). Use of the harmonic direction finder to study the terrestrial habitats of the European tree frog (Hyla arborea). Amphib. Reptilia 27, 138-142. doi: $10.1163 / 156853806776052173$

Penney, D. G. (1987). Frogs and turtles: different ectotherm overwintering strategies. Compar. Biochem. Physiol. Physiol. 86, 609-615. doi: 10.1016/0300-9629(87)90610-4

Pratihar, S., and Kundu, J. K. (2011). Life in Cold Lane: Hibernation in Anurans. Saarbrücken: Lap Lambert Academic Publishing GmbH and Co. KG.

Reiss, J. O. (2002). The phylogeny of amphibian metamorphosis. Zoology 105, 85-96. doi: 10.1078/0944-2006-00059

Roh, G., Borzée, A., and Jang, Y. (2014). Spatiotemporal distributions and habitat characteristics of the endangered treefrog, Hyla suweonensis, in relation to sympatric H. Japonica. Ecol Inform. 24, 78-84. doi: 10.1016/j.ecoinf.2014.07.009

Ryan, T. J., and Semlitsch, R. D. (1998). Migration, amphibian. Encycl Reproduc. 3:221.

Santos, R. R., Leonardi, S. B., Caorsi, V. Z., and Grant, T. (2010). Directional orientation of migration in an aseasonal explosive-breeding toad from Brazil. J. Trop. Ecol. 26, 415-421. doi: 10.1017/S0266467410000180

Scheiner, S. M., and Gurevitch, J. (2001). Design and Analysis of Ecological Experiments. New York, NY: Oxford University Press.

Schoch, R. R. (2009). Evolution of life cycles in early amphibians. Ann. Rev. Earth Planet Sci. 37, 135-162. doi: 10.1146/annurev.earth.031208.100113 
Semlitsch, R. D. (2008). Differentiating migration and dispersal processes for pond-breeding amphibians. J. Wildlife Manage. 72, 260-267. doi: $10.2193 / 2007-082$

Sinsch, U. (1990). Migration and orientation in anuran amphibians. Ethol. Ecol. Evol. 2, 65-79. doi: 10.1080/08927014.1990.9525494

Smith, G. W., and Nydegger, N. C. (1985). A spotlight, line-transect method for surveying jack rabbits. J. Wildlife Manage. 49, 699-702. doi: 10.2307/3801698

Stinner, J., Zarlinga, N., and Orcutt, S. (1994). Overwintering behavior of adult bullfrogs, Rana catesbeiana, in northeastern Ohio. Ohio J. Sci. 94, 8-13.

Storey, K. B., and Storey, J. M. (2017). Molecular physiology of freeze tolerance in vertebrates. Physiol. Rev. 97, 623-665. doi: 10.1152/physrev. 00016.2016

Stumpel, A. H. P. (1990). On hibernation sites in the tree frog Hyla arborea. Amphibia-Reptilia 11, 304-306. doi: 10.1163/156853890X00230

Sugimoto, K., and Jiang, H. (2008). Cold stress and light signals induce the expression of cold-inducible RNA binding protein (cirp) in the brain and eye of the Japanese treefrog (Hyla japonica). Comp. Biochem. Physiol. Part A Mol. Integr. Physiol. 151, 628-636. doi: 10.1016/j.cbpa.2008.07.027

Tabachnick, B., and Fidell, L. (2014). Using Multivariate Statistics 6th Edition. Carmel, CA; Harlow: Pearson Education Limited.

Todd, B. D., Luhring, T. M., Rothermel, B. B., and Gibbons, J. W. (2009). Effects of forest removal on amphibian migrations: implications for habitat and landscape connectivity. J. Appl. Ecol. 46, 554-561. doi: 10.1111/j.1365-2664.2009.01645.x

Van Gelder, J., Olders, J., Bosch, J., and Starmans, P. (1986). Behaviour and body temperature of hibernating common toads Bufo bufo. Ecography 9, 225-228. doi: 10.1111/j.1600-0587.1986.tb01212.x

Wake, M. (1982). Diversity Within a Framework of Constraints. Amphibian Reproductive Modes. New York, NY: Gustav Fischer.
West-Eberhard, M. J. (2003). Developmental Plasticity and Evolution. New York, NY: Oxford University Press.

West-Eberhard, M. J. (2005). Developmental plasticity and the origin of species differences. Proc. Natl. Acad. Sci. U.S.A. 102, 6543-6549. doi: 10.1073/pnas.0501844102

Wilkinson, A., Hloch, A., Mueller-Paul, J., and Huber, L. (2017). The effect of brumation on memory retention. Sci. Rep. 7:40079. doi: 10.1038/srep40079

Wiltschko, R., Munro, U., Ford, H., Stapput, K., and Wiltschko, W. (2008). Light-dependent magnetoreception: orientation behaviour of migratory birds under dim red light. J. Exp. Biol. 211, 3344-3350. doi: 10.1242/jeb. 020313

Wiltschko, W., Munro, U., Ford, H., and Wiltschko, R. (1993). Red light disrupts magnetic orientation of migratory birds. Nature 364:525. doi: 10.1038/364525a0

Yoo, E., and Jang, Y. (2012). Abiotic effects on calling phenology of three frog species in Korea. Animal Cells Syst. 16, 260-267. doi: 10.1080/19768354.2011.625043

Conflict of Interest Statement: The authors declare that the research was conducted in the absence of any commercial or financial relationships that could be construed as a potential conflict of interest.

Copyright (c) 2019 Borzée, Choi, Kim, Jablonski and Jang. This is an open-access article distributed under the terms of the Creative Commons Attribution License (CC $B Y)$. The use, distribution or reproduction in other forums is permitted, provided the original author(s) and the copyright owner(s) are credited and that the original publication in this journal is cited, in accordance with accepted academic practice. No use, distribution or reproduction is permitted which does not comply with these terms. 